Illinois State University

ISU ReD: Research and eData

Theses and Dissertations

5-7-2018

\title{
More Than Just a Job: A Social Enterprise's Response to Homelessness
}

Molly Cook

Illinois State University, mcook12@ilstu.edu

Follow this and additional works at: https://ir.library.illinoisstate.edu/etd

Part of the Sociology Commons

\section{Recommended Citation}

Cook, Molly, "More Than Just a Job: A Social Enterprise's Response to Homelessness" (2018). Theses and Dissertations. 931.

https://ir.library.illinoisstate.edu/etd/931

This Thesis is brought to you for free and open access by ISU ReD: Research and eData. It has been accepted for inclusion in Theses and Dissertations by an authorized administrator of ISU ReD: Research and eData. For more information, please contact ISUReD@ilstu.edu. 
MORE THAN JUST A JOB: A SOCIAL ENTERPRISE'S RESPONSE TO HOMELESSNESS

\section{MOLLY COOK}

\section{Pages}

For the first time since 2010, the number of individuals experiencing homelessness increased in the United States in 2017 (HUD 2017). A lack of affiliations with family and friends has been suggested as a cause of homelessness (Burt 1992; Jencks 1995; Lippert and Lee 2015). This study employs affiliation theory, thematic coding, and $21^{\text {st }}$ century coding methods to examine social enterprise employment as a solution to ending homelessness and increasing the number and types of affiliations individuals gain while working at a social enterprise. Seven interviews were conducted at one case study social enterprise with the goal of employing the homeless. Results suggest that social enterprise leadership staff members balance social and economic goals by facilitating increased affiliation for employees via bonding social capital with enterprise leadership and other employees as well as through bridging social capital between employees and employers and social service agencies. Enterprise leadership staff also provide an understanding environment, and employees gain increased social skills and feelings of utility through their employment, whereas enterprise leadership staff balance challenges of mental illness and high turn-over for employees. This enterprise is based in a city that has social support systems in place for individuals experiencing homelessness, allowing employees to increase their affiliations outside of the enterprise. The results suggest that social enterprise employment increases the number and types of positive affiliations for employees experiencing homelessness. KEYWORDS: social enterprise, homeless, homelessness, homeless employment, social capital, affiliation 
MORE THAN JUST A JOB: A SOCIAL ENTERPRISE'S RESPONSE TO HOMELESSNESS

MOLLY COOK

\author{
A Thesis Submitted in Partial \\ Fulfillment of the Requirements \\ for the Degree of \\ MASTER OF SCIENCE \\ Department of Sociology and Anthropology \\ ILLINOIS STATE UNIVERSITY
}

2018 
(C) 2018 Molly Cook 
MORE THAN JUST A JOB: A SOCIAL ENTERPRISE'S RESPONSE TO HOMELESSNESS

MOLLY COOK

COMMITTEE MEMBERS:

Marion Willetts, Chair

Frank D. Beck

Maria Schmeeckle 


\section{ACKNOWLEDGMENTS}

The current research would not have been possible without the guidance and mentorship of Dr. Marion Willetts. I cannot thank her enough for her countless hours of guidance and support. Dr. Frank D. Beck and Dr. Maria Schmeeckle have also been instrumental in providing wisdom and support. I would also like to thank the staff of the Stevenson Center for Community and Economic Development for the generosity of their time and never ending encouragement. Additionally, I would like to thank the staff and students in the Department of Sociology and Anthropology for being the most wonderful support system. Finally, none of this would have been possible without the love of my wonderful family in Michigan, and my wonderful friends from home.

Each and every participant in this study was generous with sharing their insights and time with me, and for that I am humbled and extremely grateful. The staff and employees of Mountain Jobs welcomed me into their enterprise and shared their world with me, and for that, I will be forever grateful.

M.C. 


\section{CONTENTS}

Page

ACKNOWLEDGMENTS

TABLES Vi

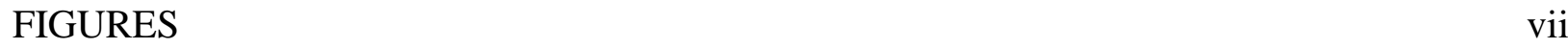

CHAPTER I: MORE THAN JUST A JOB

Introduction $\quad 1$

Theoretical and Conceptual Framework 3

$\begin{array}{ll}\text { Literature Review } & 8\end{array}$

$\begin{array}{ll}\text { Social Enterprises } & 8\end{array}$

Who Employs the Homeless? 14

$\begin{array}{ll}\text { Who is Employed? } & 17\end{array}$

What is the Impact of Social Enterprise Employment for the Homeless? 18

$\begin{array}{ll}\text { Recommendations } & 19\end{array}$

$\begin{array}{ll}\text { Data Collection and Methods } & 20\end{array}$

$\begin{array}{ll}\text { Case Study Method } & 21\end{array}$

$\begin{array}{ll}\text { Sampling } & 23\end{array}$

$\begin{array}{ll}\text { Semi-Structured Interviews } & 25\end{array}$

$\begin{array}{ll}\text { Ethics } & 27\end{array}$

$\begin{array}{ll}\text { Reflexivity } & 27\end{array}$

$\begin{array}{ll}\text { Data Analysis } & 28\end{array}$

$\begin{array}{ll}\text { Results } & 31\end{array}$

Demographic Information $\quad 31$

Employers Facilitate Increased Affiliation 32 
$\begin{array}{ll}\text { Bonding social capital } & 34\end{array}$

$\begin{array}{ll}\text { Bridging social capital } & 35\end{array}$

$\begin{array}{ll}\text { Employees Increase Affiliation } & 37\end{array}$

Balancing Social and Economic Objectives 41

$\begin{array}{ll}\text { Economic goal } & 42\end{array}$

$\begin{array}{ll}\text { Social goal } & 43\end{array}$

$\begin{array}{ll}\text { Community Resources } & 44\end{array}$

Successes and Struggles with Employing

Individuals Experiencing Homelessness 45

Successes and Struggles of Homeless Employees $\quad 47$

$\begin{array}{ll}\text { Discussion and Conclusions } & 49\end{array}$

Limitations and Implications for Future Research $\quad 57$

CHAPTER II: HOMELESSNESS IN THE UNITED STATES

$\begin{array}{ll}\text { Introduction } & 63\end{array}$

$\begin{array}{ll}\text { Motivation/Significance } & 65\end{array}$

$\begin{array}{ll}\text { Additional Literature Review } & 67\end{array}$

$\begin{array}{ll}\text { Stratification Theories on Homelessness and Poverty } & 67\end{array}$

$\begin{array}{ll}\text { Demographic Information } & 69\end{array}$

$\begin{array}{ll}\text { Causes of Homelessness } & 70\end{array}$

$\begin{array}{ll}\text { Micro level causes: poverty } & 71\end{array}$

$\begin{array}{ll}\text { Lack of affordable housing } & 72\end{array}$

Lack of employment opportunities $\quad 73$ 
$\begin{array}{ll}\text { Deinstitutionalization } & 75\end{array}$

$\begin{array}{ll}\text { Macro Level Causes } & 76\end{array}$

$\begin{array}{ll}\text { Drug and alcohol use } & 76\end{array}$

$\begin{array}{ll}\text { Dysfunctional family structures } & 77\end{array}$

$\begin{array}{ll}\text { Perceptions of the Homeless } & 78\end{array}$

$\begin{array}{ll}\text { Responses to Homelessness } & 81\end{array}$

$\begin{array}{ll}\text { Continuums of Care } & 81\end{array}$

$\begin{array}{ll}\text { Federal Plans to End Homelessness } & 82\end{array}$

$\begin{array}{ll}\text { State and City-Level Solutions } & 84\end{array}$

$\begin{array}{ll}\text { Public space legislation } & 86\end{array}$

$\begin{array}{ll}\text { Emergency Shelters } & 88\end{array}$

$\begin{array}{ll}\text { Affordable Housing } & 89\end{array}$

$\begin{array}{lr}\text { Conclusion } & 90\end{array}$

$\begin{array}{ll}\text { REFERENCES } & 91\end{array}$

APPENDIX A: RECRUITMENT ADVANCE EMAIL FOR

$\begin{array}{ll}\text { EXECUTIVE DIRECTOR } & 104\end{array}$

APPENDIX B: PARTICIPATION FOLLOW-UP CALL SCRIPT 105

APPENDIX C: EMPLOYEE RECRUITMENT PHONE CALL 106

APPENDIX D: EMPLOYEE AND MANAGER/SUPERVISOR

$\begin{array}{ll}\text { RECRUITMENT LETTER } & 107\end{array}$

$\begin{array}{ll}\text { APPENDIX E: CASE STUDY COMMITMENT EMAIL } & 108\end{array}$

$\begin{array}{ll}\text { APPENDIX F. INFORMED CONSENT FOR OWNER } & 109\end{array}$ 


\section{TABLES}

Table

Page

1. Table 1: Employee Demographic Information

60

2. Table 2: Leadership Staff Demographic Information 


\section{FIGURES}

Figure $\quad$ Page

1. Figure 1: Results Summary $\quad 62$

2. Figure 2: Sheltered and Unsheltered Homeless Individuals in $2017 \quad 69$ 


\section{CHAPTER I: MORE THAN JUST A JOB}

\section{INTRODUCTION}

As of December 2017, 553,742 individuals experienced homelessness on a given night in the United States, and approximately 3.5 million individuals experience homelessness each year (National Coalition for the Homeless 2009; Phillips 2015; Shinn 2017; The United States Department of Housing and Urban Development (HUD) 2017). This is a slight increase from $2016(549,928)$, and is the first time the United States has seen an increase in its homeless population since 2010 (HUD 2017; Weber and Mulvihill 2017). While the definition of homeless has changed over time, most recently, the U.S. Department of Housing and Urban Development defined an individual experiencing homelessness as a person who is living somewhere where humans should not live, such as an emergency shelter, transitional housing unit, or in a unit they are at risk of losing. Additionally, individuals who are leaving domestic violence situations and do not have anywhere else to live are considered homeless (National Alliance to End Homelessness 2012).

Due to increasing housing prices and increasing populations, many cities in the Rocky Mountain West and West Coast have seen an increase in homelessness in recent years. Colorado saw a 3.7 percent increase in its homeless population from 2016 to 2017 , and the homeless populations in California, Oregon, and Washington have increased by 14 percent in the past two years. Ten cities throughout the Western United States have declared a state of emergency in terms of homelessness, and are therefore ramping up efforts to end homelessness (Weber and Mulvihill 2017).

Previous research has examined both macro and micro-level causes of homelessness, with macro-level causes including a lack of affordable housing, unemployment, strict welfare requirements, and the reduction in availability of long-term mental health care facilities (Burt 
1992; Desmond 2014; Jencks 1995; National Alliance to End Homelessness 2016; Rossi 1991;

Snow and Anderson 1993). Micro-level causes include drug use, alcohol use, and lack of affiliation and severed ties with family and friends that could provide monetary or emotional support (Burt 1992; Jencks 1995; Lippert and Lee 2015). Responses to homelessness have occurred at the federal, state, and local levels, and include creating local committees of homeless service providers to coordinate efforts, called Continuums of Care, creating long-term city-level plans to end homelessness, promoting additional public assistance and affordable housing, and providing jobs for those experiencing homelessness (Burt 1992; Desmond 2014; Jencks 1995; Lee and Farrell 2003; Lee, Tyler, and Wright 2010; Lei 2013; National Alliance to End Homelessness 2016; United States Conference of Mayors 2016; Willse 2010). This research focuses on a social enterprise that employs individuals experiencing homelessness while still seeking to make a profit, as a response to homelessness.

Sudhir Venkatesh (2006) studied the Maquis Park neighborhood on the Southside of Chicago and found that due to limited job availability, limited educational opportunities, and a need to make money quickly, individuals living in the poor neighborhood, characterized by high crime, would often turn to the "underground economy" for work. Residents would partake in both licit, such as baby-sitting, and illicit activities, such as selling drugs or engaging in prostitution, to make an income in this underground economy. Service jobs that residents were qualified for did not pay enough for residents to sustain themselves, and jobs were few and far between. This research draws on Venkatesh's (2006) work to examine how a for-profit business with the goal of employing the homeless balances social and profit-making goals, in addition to exploring the impact employing the homeless through a social enterprise model has on employers, employees, managers/supervisors, and a community. This is also referred to as an 
organization having a "double bottom line," which is a business that seeks to achieve both financial and social success (Dart 2004).

The goal of this research is to examine the ways in which one case study social enterprise that employs individuals experiencing homelessness balances social and economic goals while providing opportunities to increase the number and types of affiliations for employees. A focus is placed on determining the practical implications that the executive director and managers/supervisors of the enterprise face by employing individuals experiencing homelessness, as well as the effects that being employed at a social enterprise has on employees who are currently or formerly homeless in terms of their levels of affiliation, which measures the number and quality of connections a person has to friends, family, and community members. The current study focuses on the following questions: 1.) Do employers provide opportunities for increasing levels of affiliation while employing individuals experiencing homelessness?

2.) What impact does employment have on the levels of affiliation of an individual experiencing homelessness 3.) How do employers balance social objectives with economic objectives while employing individuals experiencing homelessness? 4.) What resources do communities have in place that support a business with a goal of employing the homeless? 5.) Practically, what are the struggles and successes associated with employing individuals experiencing homelessness? 6.) What are the struggles and successes that an individual experiencing homelessness faces while working at an enterprise with the goal of employing the homeless?

THEORETICAL AND CONCEPTUAL FRAMEWORK

Theoretically, this research draws on affiliation theory, which is explained by looking at social capital. Affiliation falls on a spectrum from disaffiliation to affiliation depending on the number and depth of connections an individual has with family, friends, social services, a 
community, etc. The more connections an individual has, the lower is their risk of losing a job or housing. Social capital takes affiliation further in community development literature by examining levels of trust and a sense of responsibility individuals in a network feel to help one another (Putnam 1993). Individuals who are homeless are thought to experience high levels of disaffiliation within their family and friend networks (Rossi 1991; Barman-Adhakari et al. 2016). They may have high levels of social capital with their peers experiencing homelessness in terms of wanting to help one another, but this does not help people exit homelessness (Duneier 1999; Jencks 1995; LaGory 2010; Snow and Anderson 1993; Stack 1974). Bourdieu (1985) posited that the upper class has more affiliations than members of the lower class by having access to additional social capital in terms of access to higher levels of education, travel, and art. Affiliation theory in homelessness research suggests, likewise, that individuals experiencing homelessness have low levels of affiliation with family and friends, and lack social capital in terms of support networks in both number and quality, perpetuating their situation of homelessness.

Affiliation theory has been employed as a theoretical framework in previous research that explores the causes of homelessness in terms of examining the number and types of connections that individuals experiencing homelessness have (Eyrich, Pollio, and North 2003). Previous research has also examined the composition and function of a social network of individuals experiencing homelessness to explore the diversity of individuals in a network and their function within the network (Barman-Adhakari et al. 2016). Individuals experiencing homelessness are thought to lack human capital and have weak social capital, or connections to others that can be beneficial emotionally, socially, and in terms of finding employment or assisting with housing in emergency situations (Cherlin 2014; Desmond 2014; Putnam 1993). 
"Social isolation" has been suggested as a cause of homelessness (Royce 2015:17). Those experiencing homelessness are unable to engage in social activities requiring money, often lack the transportation to do so, and are sometimes estranged from family and friends as well (Burt 1992). Those who are homeless for longer periods of time are especially susceptible to being alienated from family and friends (Jencks 1995). While the homeless may be disaffiliated from family and friends who are not homeless, in some cases, their affiliation to other individuals experiencing homelessness, especially for the homeless living on the streets, is high

There is a continuum of affiliation from being highly affiliated with strong support networks to lacking affiliation. People who have high affiliation are less likely to become homeless or remain homeless because they have places to stay and sources of economic support from which to draw. The longer a person experiences homelessness, the more they utilize their social networks, making it difficult to continually draw from these networks. In fact, connections and support, more so than unexpected life events or education level, have been found to have a greater influence on homelessness (LaGory 1990). People experiencing homelessness, overall, are said to experience social isolation and lack connections to family and friends not experiencing homelessness (Stovall \& Flaherty 1994). While the homeless are not as attached to friends and family, it is more likely to maintain these ties if family and friends resided in the same area (Rossi 1991).

The longer a person lives on the streets, the more they increase their affiliations with other living on the streets, but the harder it is for them to escape the "subculture of street life" (Snow and Anderson 1993:41). Street friendships are different from traditional friendships; they are functional, often surface-level, and the goal is for two individuals to get off the streets together. Friendships for those living in poverty involve both distrust and practicality. When 
one person does a favor for another, the favor is expected to be returned, but both friends are often looking for ways to find the greatest benefit from the exchange (Stack 1974). This may result in hurting those who are homeless, as some refuse to leave the streets unless their friends also get jobs, delaying the process for themselves (Snow and Anderson 1993). Stack (1974) explored patterns of kinship for individuals living in poverty in a low-income area in the Midwest and found that there are "cooperative poverty networks," meaning that individuals living in poverty rely on one another for practical purposes, such as helping with childcare, but also for survival purposes, such as sharing resources to ensure that all families in a community are fed. Because a source of income is fluid for most members of a community of high poverty, the person earning an income at a given time in a kinship group is responsible for supporting the whole group because somebody else supported them while they were unemployed. This makes it difficult for people to escape poverty, even upon finding employment, because people are working to support themselves and their network of kin, including friends and extended family. Not supporting these networks would mean that if a person did lose their source of income, they would not have others in their community on which to rely (24). This is an example of high bonding social capital, which is having feelings of reciprocity, connection, or sharing resources with people in a similar social position, but it does not come at the benefit of the person who is employed and trying to escape their situation of poverty (Putnam 2000; Barman-Adhikari and Rice 2015).

When an individual is connected with other employers, housing, or training opportunities through their job, they are experiencing "bridging social capital," which is when an individual receives resources or connections outside of their own network. For example, when an individual experiencing homelessness is connected to a job or educational opportunity through a 
case worker, they are experiencing bridging social capital by being connected to someone they would not otherwise meet through their friend or family connections. Stack's (1974) study of a low-income community suggests that individuals living in communities of poverty often have strong bonding social capital, sharing both financial and time resources with one another, but lack bridging social capital in terms of access to education and jobs. Opportunities for bridging social capital increase through involvement in educational opportunities or community groups (Putnam 2000).

In addition to difficulties escaping homelessness and poverty due to intricate kinship networks, individuals experiencing homelessness who work with a case worker are stigmatized by others living on the streets and experience lower levels of affiliation while homeless with their homeless counterparts, due to their movement out of homelessness faster than their counterparts living on the streets. While it has been suggested that the longer a person is on the streets the harder it is for them to leave the streets, other research has suggested positive outcomes for those who form connections with others living on the streets (Lee et al. 2010; Snow and Anderson 1993; Venkatesh 2006). Additionally, friendships have been suggested as necessary for the "informal culture of street life," so that those who are new to homelessness learn how the streets work and how to share resources with one another (Duneier 1999:42; Ventaesh 2006).

Venkatesh (2006) explored the culture of "hustlers" in a neighborhood on the South Side of Chicago (173). Hustlers, characterized by living in precarious housing situations and who are often homeless, participate in the informal economy. Hustlers, while individualistic in terms of defending their selling space or earning an income, also maintain relationships with one another out of practicality. The current research will examine whether affiliation with regard to 
connections with employers and other employees through employment at a social enterprise is beneficial to individuals experiencing homelessness. This research will also examine if previous affiliations or lack of affiliations help or hinder homeless or formerly homeless employees. Interview responses will first be analyzed from an affiliation theory framework before exploring themes that arise organically.

Conceptually, this research will look to social enterprises as an ideal type. Max Weber (1946) describes ideal types as constructs that serve as a basis for comparison. For example, bureaucracies are ideal types, because in actuality, there is no perfect bureaucracy. According to the commonly accepted definition of a social enterprise in the United States, this research employs the definition of a social enterprise as a business that has both social and economic goals (Defourney and Nyssens 2006; Teasdale 2010). Social enterprises may exist as a subset of a non-profit organization or independently (2010). An ideal type social enterprise will balance both social and economic goals; however, no social enterprise perfectly balances its social and economic goals, and motivations are not purely social or purely economic. This research will focus on one social enterprise, with the understanding that no social enterprise is an ideal type social enterprise.

\section{LITERATURE REVIEW}

\section{Social Enterprises}

Social enterprises are businesses that combine economic activity with social goals (Defourney and Nyssens 2006; Teasdale 2010). This definition varies, however, depending on changing legal business classifications and differing social problems, such as increased unemployment or increased homelessness. During periods of heightened unemployment, for example, the definition of a social enterprise may include a component that includes decreasing 
unemployment, which has happened in Europe (Doeringer 2010). The Social Enterprise Alliance defines a social enterprise as "an organization or venture (within an organization) that advances a social mission through market-based strategies. These strategies include receiving earned income in direct exchange for a product, service or privilege." Thus, a social enterprise can exist as an independent entity or be connected with a non-profit organization (Community Wealth Ventures, Social Enterprise Alliance and CASE 2010:1).

Because of the fluidity of the definition of social enterprises, it has been challenging to obtain a count of the number of social enterprises in the United States. This has been especially difficult as many non-profit organizations may have social enterprises based on the definition of a social enterprise; however, staff members may not have knowledge of social enterprises or consider their business to be one. Since 2012, the Social Enterprise Alliance has conducted the Great Social Enterprise Census. This census is a one-minute online survey that is seeking to gain a count of social enterprises in the United States. Results have shown that of the enterprises that have participated in the census, 14,000 people in 28 states are employees of social enterprises. Additionally, 60 percent of social enterprises in the United States were established after 2006, and 29 percent were established after 2011 (Thornley 2013:1).

While there are no exact data regarding the number of social enterprises in existence in the United States due to varying definitions, social enterprises became popular beginning in the 1990's (Defourney and Nyssens 2006). Social enterprises relating to homelessness are thought to have begun with the Salvation Army selling a newspaper to support its homeless services as early as the late-1800's (Teasdale 2010). While social enterprises were not officially given a business designation until the 1970's in the United States, social enterprises that use economic activities to support social goals have been operating since the 1800's, with examples including 
The Girl Scouts selling cookies and Goodwill selling used items to provide job training for lowincome individuals (Community-Wealth 2017; Doeringer 2010). Social enterprises, however, started becoming officially recognized as a business distinction in the United States in the 1970's and 1980's due to economic struggles nationally and a reduction in government funding to nonprofit agencies (Doeringer 2010). Non-profits began to include economic activities, such as selling used items, art, or participating in other profit-bearing activities to support their budgets, and from 1982 until 2002, the percentage of funding that non-profit agencies in the United States received from profit-bearing activities increased by 20 percent (Doeringer 2010:293). Therefore, throughout the United States, social enterprises are often connected with non-profit organizations seeking additional funding (Dees 1998; Defourney and Nyssens 2006).

Social enterprises grew in Europe at the same time they were growing in the United States. While many enterprises in the United States focus on providing additional income for non-profit agencies to provide services, those in Europe focused on providing job training programs for the growing unemployed population from 1970 until the mid-2000's (Doeringer 2010). There are approximately two million social enterprises in Europe, which employ approximately 11,000 people (Doeringer 2010:307). The United Kingdom has led social enterprise development efforts in Europe (Defourney and Nyssens 2006). In 2001, the British government created a commission to study gaps in social enterprise development in the United Kingdom. They found that it was necessary to increase awareness of social enterprises, provide support to social enterprise owners, provide financial resources for enterprises, and also provide collaborative resources with for-profit businesses. As a response, the government created the business designation, Community Interest Company, which are companies that "serve a social 
impact" (Doeringer 2010:312). Since the creation of this designation, over 2,000 companies have registered as CIC's (2010:314).

Beginning in 1996, countries in the European Union formed a group called L'Emergence de l'Entreprise Sociale en Europe (EMES), which is a European research network to study social enterprises. They created a definition for social enterprises in Europe that is considered to be an ideal type definition. The EMES defines a social enterprise as an enterprise "with an explicit aim to benefit the community, initiated by a group of citizens and in which the material interests of capital investors are subject to limits" (Defourney and Nyssens 2006:5).

The Community Wealth Ventures, Social Enterprise Alliance, and The Center for the Advancement of Social Entrepreneurship conducted a survey in 2009 of 400 operating social enterprises to determine best practices in social enterprises in North America and identify trends in growth. Since the 1970's, the number of social enterprises in the United States and Canada has been increasing (Community Wealth Ventures et al. 2010). The survey indicated that nonprofits that develop a social enterprise tend to expand their enterprise over time and even develop additional enterprises. The survey also indicated that non-profits in the Western United States are more likely to have a social enterprise than are any other areas of the country, and that 41.7 percent of enterprises have fewer than five employees, while twelve percent have more than 100 employees (Community Wealth Ventures et al.2010:4). Additionally, the most common social enterprises include education and job training focused enterprises, retail or thrift shops, consulting services, food services, enterprises that focus on arts, or enterprises that exist through programs of an already existing non-profit organization.

The 2009 survey also asked survey respondents about successes and obstacles they faced in running an enterprise. Challenges include marketing, training and technical assistance, 
funding, and finding a balance between social and economic objectives (Community Wealth Ventures et al. 2010; SocEntCity 2017). Successes include developing relationships with the community and collaborating to diversify funding streams through grants and profit-bearing activities, as well as the emotional development demonstrated in employees, such as an increase in confidence (Community Wealth Ventures et al. 2010). The top cities in the United States to support social enterprises when considering regulations, quality of life, available employees, and funding availability are Washington D.C., San Francisco, Austin, Boston, Seattle, New York, Chicago, Los Angeles, and Miami (SocEntCity 2017).

Previous research has suggested that social enterprises may be used as an intervention technique to end homelessness (Ferguson 2007). Because lack of employment, as well as barriers to holding a job (such as childcare and limited transportation), have been identified as causes of homelessness, both individual entrepreneurs and non-profit organizations have created social enterprises that specifically hire individuals experiencing homelessness. Examples of these include:

- The Empowerment Plan - This organization, established in 2012, employs mothers from shelters in Detroit, Michigan to create sleeping bags that are also winter coats for people living on the streets. Since its creation, the organization has employed 34 women, and all of them have also obtained permanent housing (Empowerment Plan 2017).

- The Women's Bean Project - Based in Denver, Colorado, this program employs women with a history of homelessness, addiction, or incarceration and provides six to nine months of transitional employment coupled with social supports to reduce employment barriers (Women's Bean Project 2017). 
- Heartside Ministries - This day shelter located in Grand Rapids, Michigan, has an art studio for shelter utilizers at which visitors can create art that is sold to the general public (Heartside Ministries 2017).

Teasdale (2010) and Ferguson (2007) have studied social enterprises that employ the homeless. Employing the homeless while providing job training and other social supports, such as housing or counseling services, is considered to be a social development approach to homelessness, which tries to unite social and economic factors for at-risk populations (2007). This approach emphasizes creating learning opportunities for at-risk populations, such as the homeless, building connections through networking, providing resources for increasing financial well-being, and providing opportunities for job training (2007). This model is especially important for individuals experiencing homelessness, because the homeless are often thought to lack positive affiliations due to damaged family and friend relationships, which increases as time living on the streets increases (Cherlin 2014; Desmond 2014). Further, the longer an individual experiencing homelessness lives on the streets, the more likely they are to participate in criminal activity (Ferguson et al. 2012; Snow and Anderson 1993; Venkatesh 2006).

Teasdale (2010) examined 33 agencies and businesses that employ the homeless and determined various models of social enterprises. The first of these types of social enterprises are those that promote the mission of a non-profit agency while also creating a profit for the agency. An example of this would be the Salvation Army having a resale store. Shelters are another example of a social enterprise when they offer employment to people living in the shelter to clean or cook within the shelter for pay. Shelters are also an "accommodation provider" when their social goal is to provide housing for the homeless and they receive income from government subsidies for doing so. The "employment provider model" is one in which the goal 
of a business is specifically to employ individuals experiencing homelessness, while "training and work experience" enterprises focus on building the employable skill set of individuals experiencing homelessness, and the hybrid model is a combination of any of the models listed above (2010:26). An example of a hybrid model enterprise would be an enterprise that combines employing the homeless, provides job training, and is also affiliated with a non-profit organization. This research focuses on the employment provider model as well as the hybrid model by examining one enterprise that combines employing the homeless with other goals, such as providing job training or assistance in finding housing.

Leadbeater (2013) expands on social enterprise models by placing them into three categories: "in house services, services de proximite, and external private market enterprises" (267-268). In house services are the focus of enterprises that employ the homeless for tasks that occur strictly within an agency; for example, if a shelter hires individuals to clean the shelter in exchange for food or an income. Services de proximite are services that are provided to one or a few organizations outside of the social enterprise. An example of this would be if an enterprise creates clothes that are then sold at a commercial store. Finally, external private market enterprises provide goods or services to the public, such as in the form of a coffee shop (2013). This research focuses on a case study enterprise that is classified as a service de proximite. Who Employs the Homeless?

In the 1990s, the federal government charged the Office of Employment and Labor Training, under the McKinney-Vento Act, with the responsibility of creating a federal plan for employing the homeless. The Homeless Demonstration Program was created, which provided non-profit agencies with funding to provide individuals experiencing homelessness with employment (Whiting 1994). This program provided the homeless with job training, aid in 
finding jobs, and assistance with securing housing. After three waves of funding, the results of this program suggest that one-third of participants who were homeless were able to find jobs when there was a job training opportunity, and one-half of those individuals remained in their jobs 13 weeks later. Most importantly, it was found that providing participants with a job alone was not successful; job training and social supports were also necessary for homeless participants to retain jobs (Whiting 1994).

Funding for the Homeless Demonstration program ended in 1995 (National Coalition for the Homeless 2007). Since then, non-profit agencies, as well as individual entrepreneurs, have created programs to employ individuals experiencing homelessness. Teasdale (2010) examined 33 agencies that employ the homeless and found that employment opportunities for the homeless are most beneficial when there is a case management component, opportunities to find housing, job training, job follow up by support staff, guidance with finding public assistance, and an environment that encourages support. Additionally, employers should partner with social workers to provide social support to employees experiencing homelessness. Job providers should focus on business goals, whereas social workers should provide social support, rather than blending the two (Whiting 1994).

Non-profit agencies have created businesses that employ the homeless and generate revenue for their agency, and independent entrepreneurs have created enterprises that employ the homeless; however, jobs have been described as few and far between for those living in urban poor areas (Dart 2004; Ferguson 2007; Stack 1974; Venkatesh 2006). When non-profits create a profit-generating business they become "business-like" (Dart 2004:298). While it is possible for the goals of a non-profit agency to be similar to those of a for-profit business, agencies should be careful that they are creating clear business plans and strategic goals and are also not expanding 
too quickly for the capacity that they have. Additionally, it has been suggested that non-profit agencies that employ the homeless or provide guidance to the homeless in seeking employment should offer and encourage job training. Doing so provides opportunities for individuals experiencing homelessness to seek higher paying jobs, build their networks through professional organizations, and creates opportunities for the homeless to develop skills in technology and further their education (Collins 2016).

After studying 33 non-profit agencies that employ individuals experiencing homelessness, Whiting (1994) determined various sectors of the job market that employ those experiencing homelessness. These include therapeutic communities, professional agencies, job preparation programs, community action organizations, housing focused programs, jobs in “sheltered markets," and non-profit competitive enterprises (21). Therapeutic communities are service agencies and employers that provide a supportive and strong culture of assistance for homeless employees, whereas professional agencies are those that assist the homeless with mental health or other concerns while providing employment. Professional agencies receive their funding from community grants or other funding streams. Community action organizations also receive their funding from federal funds and promote self-help, empowerment, and resource connection for service utilizers. Housing-focused programs are agencies that primarily provide housing for homeless individuals but also connect or provide residents with employment. Jobs in sheltered markets are those that are reserved specifically for the homeless. For example, Rubicon Programs, Inc. is a corporation that reserves construction jobs specifically for the homeless. Finally, non-profit competitive enterprises and job training programs are focused on providing the homeless with public sector jobs through training and placement (Whiting 1994). 


\section{Who is Employed?}

Previous research has examined social enterprise programs that employ youth experiencing homelessness (Ferguson et al. 2012). In Ferguson et al.'s (2012) study, it was found that youth living with family and friends are 71 percent less likely to be employed, compared to their peers living on the streets or in shelters. Further, it was found that those living with a dependence on drugs are 47 percent less likely to be employed, compared to their peers who are not dependent on drugs. While more than half of the youth in the sample self-identified as being unemployed, only five percent did not earn some form of income in the preceding six months, indicating that participants were receiving public assistance or participating in the underground economy (Ferguson et al. 2012:399; Venkatesh 2006).

The Homeless Demonstration Program employed individuals ranging in age from 18 through 79 years in programs that were available to anyone experiencing homelessness, in addition to programs for specific populations, such as veterans, women, individuals with addictions, single parents, and those with disabilities. Most of those employed were single and never married, with 65 percent of participants being male and 52 percent being Black. Forty-one percent of participants had less than a high school diploma (Whiting 1994). At the time of this

study, four out of five homeless men in the general population were living alone and about 84 percent of individuals experiencing homelessness were men. Additionally, 45 percent of the homeless were Black (Burt 1989). This compares to current statistics, which show that about 60.5 percent of individuals experiencing homelessness are men and 40.6 percent of the homeless are Black (The United States Department of Housing and Urban Development 2017:9). This demonstrates that the number of individuals experiencing homelessness who are men has 
decreased by 23.5 percent since 1994, and the number of individuals experiencing homelessness who are Black has decreased by just under five percent.

A homeless employment study in Sacramento, California suggested that nearly 60 percent of individuals experiencing homelessness in Sacramento needed accommodations to maintain employment due to mental health concerns, a lack of access to transportation, or high childcare costs (Acuna and Erlenbush 2009). Further, it has been suggested that employment through a social enterprise is not as beneficial for those who have "complex needs," such as mental illness or addiction (Leadbeater 2013:266; Teasdale 2009).

What is the Impact of Social Enterprise Employment for the Homeless?

Employment for the homeless is thought to increase self-esteem and has been seen as “therapeutic" for those who also have mental illness (Whiting 1994:11). Additionally, replacing illicit street activity with licit market activity reduces criminal charges among the homeless and increases the stability in their incomes. While there have been positive outcomes for homeless employees who work at social enterprises, people have questioned whether social enterprises are focused enough on the needs of the homeless outside of employment (Leadbeater 2013; Teasdale 2010). As enterprises focus more heavily on the business and profit-producing aspect of their business, they are less likely to address the biopsychosocial needs of their employees, such as mental illness, confidence, and workplace happiness (Dart 2004; Leadbeater 2013). Others have argued that the skills that homeless employees gain in social enterprises are not the skills that make them viable applicants in the public sector. For example, agencies in the United Kingdom have employed the homeless to complete construction work, but the construction market is already saturated (Leadbeater 2013). Additionally, job availability and the amount of support varies widely based on geographic location (Whiting 1994). 


\section{Recommendations}

To be most effective, social enterprises should provide homeless employees with a “strong culture," emphasizing support with an equal emphasis on housing, employment, and connection to social services, which also results in increasing the number and types of affiliations they have (Whiting 1994:29). According to Leadbeater (2013), social enterprises should create clear strategic plans to ensure that employees not only have a job, but also a way out of homelessness. These strategic plans are suggested to avoid the process of mission abandonment, in which enterprises begin to focus their business more heavily on profits and abandon social goals, such as helping employees obtain housing (Dart 2004).

Previous research has suggested that housing-based programs, such as working in a shelter, and sheltered market programs, such as businesses that employ only homeless individuals and do not allow for interaction with other housed employees or clients, are not helpful for the homeless because they do not allow for increased affiliation through contact with employees and employers in the public sector. Further, the conditions of these programs are thought to be unrepresentative of positions in the public sector; however, these jobs do promote an increase in job skills regardless of how reflective they are of the marketplace. Ultimately, the goal of any employment program should be to provide a gateway to permanent employment (Whiting 1994). Two examples of programs that do this are Homeboy Industries in Los Angeles and Ashbury Images in San Francisco. Homeboy Industries employs former gang members, some of whom are homeless, and provides them with a job in a bakery while connecting them to social services. Ashbury Images provide jobs to individuals experiencing homelessness or struggling with substance abuse while providing workshops to build job skills and self-esteem (Ferguson 2007). 
Based on a 2009 survey of homeless participants in Sacramento that measured job preparedness, job skills, and work history among a sample of 182 homeless participants, the Employment Committee of the Sacramento Ending Chronic Homelessness Initiative provided recommendations for employing the homeless. First, localities and social enterprises should connect employees with affordable housing to help them maintain employment. Cities should also host Homeless Employment Summits at which employers strategize and collaborate to increase homeless employment. Increasing affordable health care and promoting education surrounding employing the homeless will assist in job retention, in addition to providing accommodations for homeless employees with disabilities. Additionally, increased access to transportation, phone, and email will aid the homeless in finding a job. Finally, federal and local level plans to end homelessness should be constantly updated and revised with new, timely and attainable goals (Acuna and Erlenbusch 2009).

\section{DATA COLLECTION AND METHODS}

The goal of this research is to examine the ways that one case study social enterprise that employs individuals experiencing homelessness balances social and economic goals while providing opportunities for employees to increase their affiliations. This goal was accomplished by asking the following questions utilizing an ethnographic framework: 1.) Do employers provide opportunities for increasing levels of affiliation while employing individuals experiencing homelessness? 2.) What impact does employment have on the levels of affiliation of an individual experiencing homelessness 3.) How do employers balance social objectives with economic objectives while employing individuals experiencing homelessness? 4.) What resources do communities have in place that support a business with a goal of employing the homeless? 5.) Practically, what are the struggles and successes associated with employing 
individuals experiencing homelessness? 6.) What are the struggles and successes that an individual experiencing homelessness faces while working at an enterprise with the goal of employing the homeless? A case study and semi-structured interviews are the methods used in the current research.

Luker (2012) suggests three ways to draw conclusions in ethnographic research, including comparing to standard knowledge, comparing the research case to another case, or comparing research to previous theory. This research looks to previous research on social enterprises and employing individuals experiencing homelessness as other cases and employs theories on affiliation to draw conclusions.

\section{Case Study Method}

One social enterprise that employs individuals experiencing homelessness is the case study site for this project. Previous researchers who have studied social enterprises have also utilized a case study methodology (Leadbeater 2013; Teasdale 2010). Yin (1994) explains that case studies are effective; however, they should be used to describe, not to generalize to broad cases. Additionally, Dart (2004) utilizes a case study method and explains that when choosing case study sites, it is important to find sites that fit a researcher's conceptual framework. Therefore, this case study site is a social enterprise that is currently operating with a goal of employing the homeless, and results are specific to this social enterprise.

The case study social enterprise for this project is Mountain Jobs. Mountain Jobs is located in a mid-sized city in the Western United States. Mountain Jobs' leadership staff members aspire to connect job seekers with temporary to permanent employment and support them through the process. Established in December 2016, Mountain Jobs is a social enterprise that benefits Mountain Faith Coalition, a faith-based social service agency that includes a 
rotating family shelter at area churches, in addition to including housing advocates and case managers for individuals experiencing homelessness. According to enterprise leadership staff, the initial goal of Mountain Jobs was to provide work for individuals in the community experiencing homelessness or who have a criminal record, and create a self-sustaining, for-profit entity at the same time that supports Mountain Faith Coalition. Over time, it has evolved to assist anyone seeking work; however, the majority of the employees are chronically homeless (about 50 percent) or living in transitional housing or couch surfing (about 15 to 25 percent), and the leadership staff intentionally seeks to recruit employees experiencing homelessness. Mountain Jobs is staffed by an executive director and manager, and the supervisor of the entity is the director of Mountain Faith Coalition as well as a member of the Board of Directors of Mountain Jobs.

Mountain Jobs has two entities: Mountain Jobs itself, which serves as a staffing agency in which the executive director, Heidi, connects employees with employment in partner businesses, typically housekeeping jobs, dishwashing, and employment at hotels, and the Work It Team, which is a group that completes small contracting projects, such as painting, snow removal, and home repair. While Heidi seeks to find employment for employees in businesses throughout the community through Mountain Jobs, the Work It Team is an entity in itself, where the primary employer is Mountain Jobs. Individuals will hire the Work It Team to complete small projects, and Mountain Jobs will employ staff to complete those projects. Employees go to either Mountain Jobs' partner businesses or join the Work It Team as temporary staff members. Partner businesses hire employees for a four, eight or sixteen week contract, and a multiplier is attached to the baseline hourly wage paid to the employee, which Mountain Jobs keeps. For example, a hotel could hire employees for four, eight, or sixteen weeks. If the employees' wage 
is $\$ 10$ per hour, the employer would pay a 1.65 multiplier on top of that wage, which Mountain Jobs uses to pay for supporting costs, such as insurance. Mountain Jobs is a low-risk opportunity for employers because they are not paying the costs of onboarding a new employee, they can determine if the employee is a good fit before offering them a permanent position, and Mountain Jobs handles all human resources aspects and recruitment. For example, if an employee will be late for work, they would call Heidi, and Heidi would call the partner business.

Mountain Jobs is currently on its second executive director, and all leadership staff members anticipate growth in the coming years. From March through October of 2017, 38 people were employed through Mountain Jobs.

\section{Sampling}

A list of social enterprises with the goal of employing the homeless in locations convenient to the researcher was compiled while gaining IRB approval. As was discussed earlier, social enterprises that are services de proximite or external market services were considered (Leadbeater 2013; Teasdale 2010). These businesses fall into either the hybrid social enterprise model or employment provider model. Upon IRB approval, a purposive sampling method was utilized, which is choosing a sample based on specific characteristics a researcher has determined to be significant for the purpose of the research (Collins 2016). For the current research, social enterprises were identified that have a goal of both employing the homeless and making a profit. Potential case study enterprises were not contacted until after gaining IRB approval.

A representative of the first case study site contacted (Mountain Jobs) agreed to participate in the study. The executive director, Heidi, was contacted twice to solicit participation. The first contact was via email with an advance letter (see Appendices). This 
letter explained that the researcher would be contacting her via phone in the next few days to discuss the research and schedule a time for an interview. Three days after sending the email, the researcher contacted Heidi via phone. She agreed to participate in the study and scheduled an interview at that time.

After Heidi agreed to have Mountain Jobs serve as the case study site for this project, a confirmation email was sent so that the objectives and steps in the project were understood. The executive director (Heidi) was the first participant interviewed. She then provided to the researcher a list of the current enterprise employees and their contact information so that they could be contacted to schedule interviews. After talking to the employees on the list, it was determined that five of them met the criteria to participate in an interview; four chose to participate. Employee participants are above 18 years of age and are not overtly mentally ill. Employees also worked at the social enterprise for at least eight weeks prior to participation, and work at least 20 hours per week on average.

Potential employee participants were contacted in two waves. First, employees were called and asked if they would like to participate in the study. Then, they were emailed a recruitment letter, and if they were interested in participating, they emailed the researcher to schedule an interview at a time and place convenient for them. Interviews were conducted at a shelter, the public library, a coffee shop, and a social service agency.

Two enterprise leadership staff members were interviewed, in addition to the executive director. One leadership staff member, Robert, is the supervisor of Mountain Faith Coalition, and oversees Mountain Jobs and is on the board of directors. Aaron, the manager of the Work It Team, was the other leadership staff member participant. [At the time of interviews, three leadership staff members worked at least 20 hours per week and worked at the enterprise for at 
least eight weeks; however, two staff members stopped working at the enterprise prior to their scheduled interview. Therefore, one leadership staff member (Aaron) was interviewed after being on the job for three weeks as he was the next longest-employed leadership employee.] Aaron and Robert were contacted in three waves. First, they were given a recruitment letter in person. After three days, they were called to determine whether they were interested in participating. After indicating a willingness to participate, the time and location of the interview was then determined via email. Both interviews were conducted in the church where the social enterprise offices are located, but in a separate room and in a different area from the social enterprise office. The social enterprise offices themselves are a central place for meeting with employees, and employee work, aside from the leadership staff's work, does not actually take place in the enterprise offices.

\section{Semi-Structured Interviews}

Data collection occurred through open-ended, semi-structured interviews. Employees, the enterprise director, the manager, and the supervisor were interviewed separately. Participants were informed of the potential risks to confidentiality on the informed consent forms they signed prior to participating in an interview. Participants were given pseudonyms and all attempts to maintain confidentiality were taken. The uses of this research were also described to participants, and participants were given an opportunity to request a copy of the final report. Interviews were audio recorded and transcribed using a voice recorder, and extensive notes were also taken during the interviews. Interview guides were prepared to guide the interviews. Interview guides are available in the appendix.

To answer the research question, "Do employers provide opportunities for increasing levels of affiliation while employing individuals experiencing homelessness," leadership staff 
members were asked to explain their prior work history and the referrals they provide to employees in terms of social services and job resources. Employees were asked to describe the relationships and connections they have gained as a result of an employer-facilitated connection. Employees, the manager, and supervisor were asked biographical questions and questions about how their job has impacted their life to answer the question, "What impact does employment have on the levels of affiliation of an individual experiencing homelessness?" The question, "How do employers balance social and economic objectives while employing individuals experiencing homelessness," was answered by asking enterprise owners and managers/supervisors questions about social support and job training that they provide to employees and about the culture of the enterprise. Culture was defined as the commonly understood beliefs, common rituals and ways of speaking, and ongoing ceremonies, meetings, or activities in an enterprise (Swidler 1986). The question, "What resources do communities have in place that support a business with a goal of employing the homeless," was answered by asking leadership staff about their collaboration with social services and other community businesses (Fergus and Ramsden 2006). The executive director, manager, and supervisor were also asked questions about the struggles and successes of the business to answer the question, "Practically, what are the struggles and successes with employing individuals experiencing homelessness?" Employees, the manager, and supervisor were also asked questions about their experience working at the enterprise to learn about the struggles and successes they face in being employed at a social enterprise. One social enterprise leadership staff member was homeless, whereas the other two leadership participants were not, so there was a set of questions for the participant who had been homeless and a set for those who had not been homeless for analytical purposes. 
Interviews lasted approximately 40 to 75 minutes, and were recorded and transcribed. Interview questions began with a biographical component, which are general and broad questions about the interviewees' lives. This helped to establish rapport early during the interview (Fontana and Frey 1994). The questions that necessitated longer and more in-depth answers were placed in the body of the interview. Additionally, interview questions slightly changed as interviews progressed to ensure that commonly understood language was used (DeVault 1996; Fontana and Frey 1994).

\section{Ethics}

Two ethical concerns arose throughout the research process. The first involved two employees indicating sadness in their housing situation. When such sadness arose, the researcher, the researcher provided to them a list of mental health and housing resources in the community that had been prepared in advance. The second ethical concern was the possible breach in confidentiality if the employer were to discover that an employee participated an interview. To prevent the risk of a breach in confidentiality, the social enterprise was provided with a pseudonym as were all participants.

\section{Reflexivity}

Altheide and Johnson (1994) report that few researchers use reflexive methods to examine their experience as a researcher. Reflexivity is the process a researcher takes in considering their own experiences and how that shapes and forms the research. The researcher did this by first considering that she is a White woman from a middle class background. This will shape the way she views enterprises as well as the way she views homelessness. The goal of this project is to describe a social enterprise that employs individuals experiencing homelessness 
and its impacts on the executive director, manager, supervisor, individuals experiencing homelessness, and communities, so she attempted to focus on that goal throughout the project.

Coinciding with the reflection on how the researcher's race, gender, and socioeconomic status influence this research, she continually sought to determine whether this research is seeking to create a better situation for individuals experiencing homelessness, which is in line with the spirit of feminist research methodology (DeVault 1996). This researcher exercised caution in departing from some previous research, which has "mirrored pathological and cultureof-poverty interpretations of people of color and of the poor in conformity with historically specific folk beliefs in the dominant societal culture" (Stanfield II 1994: 178). The researcher addressed this issue by focusing on discussing the experiences of participants without inflicting White, middle class meaning on these experiences. This research focuses on structural road blocks and triumphs in terms of opening and sustaining a social enterprise without perpetuating racial stereotypes.

\section{DATA ANALYSIS}

Analysis for this research utilizes methods from grounded theory analysis, 21 st century qualitative coding methods, and thematic coding (Braun and Clarke 2006; Corbin and Strauss 1990; Deterding and Waters 2017). Previous researchers have employed grounded theory methodology to analyze qualitative data while studying social enterprises (Ferguson et al. 2012). However, recent analysis of qualitative coding has suggested that there is a lack of emphasis on describing grounded theory coding methods by qualitative researchers (Braun and Clarke 2006). Grounded theory coding has historically involved a researcher searching for themes that emerge from their qualitative data and developing theory from those themes (Deterding and Waters 2017). Grounded theory methodology, while allowing for theory development and comparison 
after themes have been developed, does not involve extensive literature review prior to research and is a lengthy and rigorous process involving complete transcription and the coding of each line of qualitative data. This makes analysis difficult for researchers with a large sample or researchers early in their qualitative research careers. Due to Institutional Review Board requirements calling for literature review prior to conducting research and a push to find and fill gaps in research, grounded theory methodology is not always appropriate as a sole method of analysis (Braun and Clarke 2006; Deterding and Waters 2017). Therefore, data for this research are analyzed using some methods from grounded theory methodology, but 21st century qualitative coding and thematic coding methods are also employed. This research is testing affiliation theory; therefore, aspects of grounded theory, such as coding and analyzing data as they are collected are utilized, but affiliation theory is being tested rather than building a new theory based on data collected.

The first step of the grounded theory method involves simultaneously analyzing data while collecting them, which means that interview questions could change as themes emerge through the course of completing interviews. Additionally, concepts identified through codes will build theory at the end of the research. So, coding focuses on identifying concepts. Updates to grounded theory methodology, termed 21st century qualitative coding by Deterding and Walters at a presentation at the 2017 American Sociological Association meetings, involves semi-structured transcription in which interviewee responses are transcribed, but filler words, such as "umms," are omitted. Data are first indexed and memos are created describing indices. Unlike individual line coding in grounded theory coding, indexing involves coding large portions of data. Indexing also involves locating meaningful quotes and identifying themes across transcripts. Themes are described through memos. The next step involves analytic coding, which 
relates themes to existing theory. The final step involves examining the validity of theories and themes by re-examining transcriptions. The benefits of this method are that it is a less tedious coding method for research with a large number of participants, and the process of indexing allows for quick identification of larger themes. The limitations of this method for this study is that the sample for this research is small and coding software, such as NVIVO, was not employed, despite 21 st century coding assuming the use of coding software (Deterding and Walters 2017).

Thematic coding is thought to encompass several qualitative data analysis methods, including grounded theory methods and 21 st century coding methods. Thematic coding is suggested as a coding method for researchers early in their qualitative research careers because it involves transcribing loosely, similar to 21 st century analysis, allowing a researcher to become familiar with their data while not getting too bogged down in transcribing. Next, initial codes are created by looking at each line of data, which are then merged to create themes and sub-themes. After themes are generated, they are reviewed to ensure that they are exhaustive, comprehensive, and representative of the data. After this check of validity, themes are named to capture the essence of the theme and subthemes. This method produces themes that are easy for laypeople to understand, and is thought to be a good way of capturing key themes from a large amount of data (Braun and Clarke 2006).

Drawing on parts of grounded theory methodology, the first step of analysis is constant comparison. The researcher simultaneously analyzed data while collecting them, which means that interview questions changed slightly as themes emerged throughout observations. After data collection, interviews were transcribed using partial transcription methods, following thematic coding and 21 st century coding methods. Using the theoretical framework of affiliation theory, 
transcriptions were initially coded to determine how the affiliations of individuals experiencing homelessness are affected as a result of their employment at a social enterprise and how employers facilitate increased affiliation for individuals experiencing homelessness. Then, using a grounded theory methodology, transcriptions were coded to determine any additional emerging themes. Transcriptions were coded in the following steps: 1.) Following transcription, initial coding demonstrated emerging themes and sub-themes. 2.) Once themes and sub-themes were determined, larger portions of data were indexed. 3.) Next, memos were created, which provided detailed explanations of themes and linked themes across interviews. The first type of memo that was created is an elemental memo, in which themes and sub-themes are described, generally briefly. 4.) The generation of sorting memos occurred next, which entails combining elemental memos. 5.) Finally, memos were compiled to complete an analysis of themes from interviews. The indices that were created allow for a quick search of themes across transcriptions.

\section{RESULTS}

\section{Demographic Information}

Seven participants were interviewed - three enterprise leadership staff members and four employees who worked at least 20 hours per week on average and were employed by the enterprise for a minimum of eight weeks prior to the interview. Two of the employees, Don and Kurt, are employed with the Work It Team, and two employees, Heather and Carly, work for businesses in town through Mountain Jobs. Enterprise leadership staff participants include the executive director of the enterprise, Heidi, the Mountain Jobs supervisor/board member/director of Mountain Faith Coalition, Robert, and the manager of the Work It Team, Aaron. All leadership staff interviewed hold full-time positions, and two participants worked at the enterprise for at least eight weeks prior to the interview; however, Aaron, the manager of the 
Work It Team, worked at the enterprise for three weeks prior to the interview, which was the longest-employed managerial position due to recent turn-over.

Additional demographic information is included in Tables 1 and 2. Table 1 includes employee demographic information. One employee participant, Heather, was experiencing her first period of homelessness over her lifetime, and Kurt, Jon, and Carly had previously experienced periods of homelessness. All four employee participants attained at least a high school degree/GED, with two participants earning associate's degrees, and Heather having attained some college. Considering that Mountain Faith Coalition is a family shelter for those experiencing homelessness, three participants have children. Additionally, three participants have a prior record with the court.

Table 2 includes demographic information about enterprise leadership staff. All three enterprise leadership staff members have children, and one leadership staff member, Aaron, the manager of the Work It Team, previously experienced homelessness. All three leadership staff members also have attained at least a Bachelor's degree, with the executive director of Mountain Jobs (Heidi) and the supervisor of Mountain Jobs/director of Mountain Faith Coalition (Robert) both having earned Master's degrees. Heidi previously worked in law enforcement, Robert has a background in social work, and Aaron also owns a waste management business.

\section{Employers Facilitate Increased Affiliation}

The research question, "Do employers provide opportunities for increasing levels of affiliation through social objectives while employing individuals experiencing homelessness," was explored by asking Heidi, Robert, and Aaron questions about providing connections for employees to social service agencies, community members, and employers. When interviewing employees, the research question, "What impact does employment have on the levels of 
affiliation of an individual experiencing homelessness" was explored by asking Don, Heather, Carly, and Kurt questions about their relationship with co-workers, employers, enterprise staff, and community members.

Broadly, in terms of affiliation, all employees indicated a negative affiliation with at least one family member. Carly and Kurt are separated from all of their children, and Don has one biological child living apart from him, but does live with his partner's three children. Additionally, a common theme among employees and one leadership staff member is a negative affiliation with a former employer. For Heidi and Heather, this was a wrongful termination by their prior employer, and for Don and Kurt, this was experiencing a negative termination due to substance use or a prior court record. However, six of the seven participants (everyone except Heidi) indicated that a positive affiliation with either Alcoholics Anonymous, a case worker, or a friend who connected them with their current job at Mountain Jobs.

The enterprise leadership staff provides opportunities to increase the number and types of affiliations employees have through processes of bonding social capital and bridging social capital. Bonding social capital occurs when individuals are connected to others and share resources within their own groups (Putnam 2000; Barman-Adhikari and Rice 2015). Bridging social capital occurs when an individual increases connections or receives resources from outside of their personal network (Putnam 2000; Barman-Adhikari and Rice 2015). Bridging social capital increases affiliations for individuals experiencing homelessness when they relate to individuals outside of their networks who can assist them in ending or avoiding homelessness, such as social service agencies, employers, or co-workers who are not experiencing homelessness. 


\section{Bonding social capital.}

Employers facilitated bonding social capital by explaining the shared experiences they had with employees, which increased feelings of trust between employees and enterprise leadership. Heidi indicated a passion for her work because of her experience as a single parent and prior difficulty obtaining employment. Aaron also showed passion for his work due to a prior experience with homelessness. Heidi explained her early days in her position, saying

So, people were walking through that door, and every person who walked through that door had a different story: they were sleeping on a couch, they had just moved here from another place, they had no housing, and thankfully we were just coming out of the end of winter, but everybody has a need, and everybody has a story. I understood that story because I was in that position. I wasn't homeless, but I understand what it's like to call a place and be like "I need a job." Who's pushing for me to help me get a job?"

Additionally, three of the four employee participants (Heather, Don, and Kurt) indicated a sense of connection with enterprise leadership staff due to shared experiences, and all employees indicated feelings of trust and respect for Heidi specifically. It was more common for employees to discuss their strong connection with Heidi when discussing their successes at the social enterprise than to discuss their actual job itself. Heather explained,

She's [Heidi] trying really hard. Everyone I've met through that crew [Mountain Jobs], they do. They work their rear ends off. They got to fight fires, you know, and it's really awesome, her being a single mom, and fighting for all of us at the same time. It just gives me that much more hope and faith in Mountain Jobs that I really do, I really do hope it's successful. I really do.

Employees and leadership also emphasized the importance of enterprise leadership staff having a connection to the social mission of the enterprise; to connect stigmatized individuals (specifically the homeless) with jobs and support. A common anecdote participants shared was of a former Work It Team supervisor who did not have a connection with the mission to support the homeless. Robert explained, "We hired someone who didn't have the heart for what we are doing," emphasizing the importance of staff feeling connected to the social mission of the 
enterprise. During interviews with Heidi, Robert, and Aaron, it was not uncommon for them to share a story of a specific employee who they felt connected to and showed excitement when telling their story of success in exiting homelessness.

Bonding social capital also occurred when employees refer friends and family members to employment through Mountain Jobs who are experiencing homelessness. Carly indicated that she referred both her husband and aunt to Heidi to help them obtain employment, and Kurt and Heather indicated that they often refer individuals from the local homeless shelter to Mountain Jobs. While Don, Carly, and Kurt indicated that they were estranged from family members and their children, each of them did have some remaining family connections. Kurt is in contact with a few of his siblings, and Don and Carly each have a spouse or significant other. None of the employee participants indicated that their job negatively impacted any of their already existing family or friend relationships. Perhaps this is because they are able to refer their family and friends experiencing similar situations of vulnerability to Mountain Jobs.

\section{Bridging social capital.}

The theme of bridging social capital was one of the most common themes among employee and leadership staff interviews. Participants discussed connections with individuals outside of their networks or social class as a result of their employment through Mountain Jobs in two ways. This theme arose most commonly by explaining that Heidi, the executive director, connects potential employers to homeless employees. For example, Heidi explained that a large part of her job is explaining to potential employers the stories of individuals she is trying to help with finding a job. Heidi connected Heather with a temporary housekeeping position at a hotel with Mountain Jobs, and Heather is now a full-time employee with the hotel, and has received two promotions. 
Another sub-theme discussed was community members forming relationships with individuals experiencing homelessness, which is facilitated by the social enterprise through their relationship with church congregations. Kurt explained this when he told the story of how he became involved with his church. He explained that a church member hired him through the Work It Team to complete a roofing project. During his time on the job, Kurt formed a friendship with the client and now goes to church with him, where he has found friends and a sense of community. Kurt explained, "Anyway, he [a client] invited me to his church so I go. I've been going every week..... Yeah, it's a good church. It's not rock and roll Jesus; it's more traditional. And, they don't care what you believe. They teach Jesus. They're cool people.” Robert, the supervisor of Mountain Jobs, also explained that church members will have employees over to their homes to socialize. He remarked, "A huge part of the customer base is a bunch of our church folks, and so they hire people to do whatever. So, that's been, they've been a huge part of the customer base for it. And then also, we hear all the time, you know, they're [employees] also just going over and hanging out with people at their places," demonstrating the connection between employees and clients not just on a work-level, but also socially. These connections are examples of both bridging and bonding social capital. When an employee is connected with a church member to complete a job, bridging social capital is occurring, however, when an employee becomes friends with a church member, bonding social capital is occurring because the employee and church member is in the same social network (the church congregation).

Along the same vein of the theme of connections with church congregations, a common theme among all leadership staff participants is the enterprise's religious affiliation. Heidi, Kurt, and Robert mentioned that the religious affiliation of the organization creates a more 
understanding and collaborative environment. For example, Heidi stated, "I think what is most satisfying here is being an organization based on faith, and just this interfaith connection of people and super proud of the org. that we are. This is very familial.” Additionally, Kurt explained that because the enterprise has a religious affiliation, he and others in town assume that the enterprise is attempting to contribute to the community. This affiliation could help increase the rate at which employees trust leadership staff and clients, as the religious affiliation gives the enterprise credibility that it desires to improve the well-being in the community.

Aaron, the manager of the Work It Team, emphasized the importance of enterprise leadership staff having community connections prior to their employment with Mountain Jobs so that they are able to bridge social capital. He remarked, "So, I already have established community ties and networking within the community, both with the individuals seeking employment, and then also, just the at-large community, who I've been working with over the years." Indeed, the Work It Team started as a result of Heidi connecting an employee with her friend who needed some help around the house. Additionally, Kurt, Don, and Heather all explained that they were aware of how connected Heidi is in the community and that her former job in law enforcement helped her to have many community relationships. Kurt remarked, "It was really nice because it seems like Heidi knows a lot of people in town, of course. I heard a little about her, she used to be with the sheriff's department and stuff like that and she knows who I am, I believe," demonstrating that Kurt understood, even prior to working at Mountain Jobs, Heidi's community connections.

\section{Employees Increase Affiliation}

Employees experience an increase in positive affiliations by developing friendships with co-workers, forming a relationship with Heidi, the executive director, and clients, and through their connections to social service entities as a result of their social enterprise employment. 
These social service agencies include housing advocates through Mountain Faith Coalition or parenting resources. Because Mountain Jobs receives referrals for employees from individuals staying in the Mountain Faith Coalition shelter and vice versa, Mountain Jobs has a pipeline for employees. Employees either enter Mountain Jobs via Mountain Faith Coalition housing or via outside housing. If they are already living in the Mountain Faith Coalition Shelter, as do Don or Heather, they will be connected to Mountain Jobs if they are seeking employment. Heidi, the executive director, then connects employees to social services they have not already been connected with through Mountain Faith Coalition, such as a parenting center in town on whose board Heidi serves. If an employee comes to Mountain Jobs and is not living in the Mountain Faith Coalition shelter, as is the case with Carly or Kurt, Heidi will connect them to a job, and then connect them to a housing advocate and case worker through Mountain Faith Coalition, in addition to any outside social services of which she is aware.

Employees also increase positive affiliations through bonding social capital as they form relationships with their co-workers. Heather noted that her co-workers provided her with leads on housing. Kurt explained that he tried to help a new homeless employee with banking when they received their first paycheck. Kurt described himself as being not a mentor to his coworker, but instead is simply attempting to assist him. He also explained that as one of the few employees who can drive, he is happy to give his co-workers a ride to work whenever he can, and he seeks to donate a portion of his paycheck back to his church and the services he utilizes. Kurt explained, "Yeah, I take my money trying to do good things with it - saving it, giving it, helping people out. Um, what else? I don't know. Tithing at church.” In stating that he is trying to do "good things" with his money, Kurt is demonstrating his willingness to give back, as he receives assistance from the community in the form of shelter at the local homeless shelter. 
Employees also increase their positive affiliations by developing relationships and a sense of trust with leadership staff, particularly with Heidi. Carly explained that if she ever needs a reference for a job, she knows she can count on Heidi to provide her with one. Also, Heidi, Robert, and Aaron expressed a sense of deep caring for the health and safety of employees. Heidi explained that employees will send her selfies on the job, and she encourages them to do so when they have "a win," such as completing a large project, receiving a promotion, or earning an award at work. She also expressed deep care and concern for employees as she said she tries to find them food or gloves if she knows they are without. Having been without an advocate when she was searching for a job, Heidi has stepped into the advocacy role, and having that source of support was explained as being important to all employees in finding housing and obtaining employment. Heidi explained, "So, the difference between us and other staffing agencies is that we know the stories of the people who are walking through the door. We're not guiding them to a computer to fill out some paperwork because that just doesn't work for everybody." Heidi's statement is a testament to her dedication to get to know each employee and know each employee's individual needs.

Clients not only provide employees with work, but also maintain connections with employees in some cases. Don explained, "She likes her yard done a particular way," when describing a client who frequently requests him for work. This particular client specifically asks for Don to complete projects at her home when she calls Mountain Jobs, and Don explained that she has indicated wanting to hire him separately on a more frequent basis in the future. Carly also explained that she received an award at work for being one of the best housekeeping/cleaning employees one month. Heather works for an outside client full-time as a result of her original connection with the client through Mountain Jobs. Since beginning her 
employment with the client through Mountain Jobs in March, Heather has received three

promotions. Heidi explained the promotions and successes that employees from Mountain Jobs receive by emphasizing that people who come through Mountain Jobs are, for the most part, hard workers who need a chance, and employers have found that to be true. Robert affirmed Heidi's belief that most employees are hard workers, saying

The success specifically with staffing people who are currently homeless, they have been good employees for people - they really have been very committed, very good employees....I'm pretty sure that anyone who has been previously homeless that has been placed or connected with a business has done really, has been able to stay there.

If an employee ever severs a relationship with a client due to their own behavior or a choice on the employer's part, Mountain Jobs will no longer work with that employee, although they can continue to remain in the Mountain Faith Coalition shelter.

While employees experience increased affiliation with employers, co-workers, and enterprise leadership staff, two participants expressed frustration with their co-workers who were also experiencing homelessness. Don indicated that one of his co-workers is too bossy, and Carly indicated that she did not feel a deep connection to her co-workers. Both Carly and Heather, who have both co-workers who are experiencing homelessness as well as housed coworkers, indicated feeling a bond to their co-workers who are housed either by receiving housing leads or working productively together, but did not indicate that same bond with their fellow unhoused co-workers. This indicates that increasing affiliations with individuals who are housed can help to provide a safety net for individual experiencing homelessness, with additional individuals to draw from if they are at risk of homelessness in the future after being housed. 


\section{Balancing Social and Economic Objectives}

The question, "How do employers balance social objectives with economic objectives while employing individuals experiencing homelessness" yielded themes that include partnering with a social service agency, creating an understanding environment, and advocating for employees. Both enterprise leadership participants and employees indicated that Mountain Jobs has both social and economic objectives. All participants were able to point to a social goal to which the enterprise aspires, which is either connecting vulnerable populations to employment opportunities or assisting individuals to develop their social skills through employment. Aaron, the manager of the Work It Team, noted that the social goal of the organization is "getting the person to feel connected again," and that other goals are secondary. Heidi and Robert indicated that the goal is split between making a profit to fund Mountain Faith Coalition and working to employ vulnerable populations. However, both also indicated that the social goal does slightly outweigh the economic goal. Heather and Carly indicated that the goal of Mountain Jobs is social - to get people working. Don and Kurt identified both social and economic goals of the enterprise throughout the interview. Socially, they pointed to connecting vulnerable populations with employment, and economically, Don made the following comment, suggesting an economic goal of the enterprise: "Once they [the client] found out that they [Mountain Jobs] were making $\$ 15$ and I was only make $\$ 10$, they were like, it should be the other way around, they should be doing $\$ 10$ and you should be doing $\$ 15$." Don expressed frustration here because he believes that he should be making more money than does the enterprise. Kurt also explained that based on his credentials and former job experience working in roofing, he should be making significantly more money than he does through Mountain Jobs. However, due to difficulties in finding employment as a function of his court record, he accepts the Mountain Jobs position. 
Carly and Heather did not express discontentment about their income from their employment at Mountain Jobs. Both Carly and Heather discussed that they loved the way their job made them feel, but never mentioned the amount of income they made from their job. Heather, for example, stated "I like the fact that when I'm there, I'm appreciated," referring to her time at work. Additionally, Carly and Heather both work through Mountain Jobs in service industry positions, whereas Kurt and Don work for the Work It Team in manual labor positions, which could contribute to levels of satisfaction with pay.

\section{Economic goal.}

The three enterprise leaders indicated that the profit made by the social enterprise is specifically intended to allow the shelter affiliated with Mountain Faith Coalition to be selfsustaining. Additionally, Heidi and Robert indicated that Mountain Jobs was not initially profitable and had relied on grants, donations, and other sources of funding during their first year of operation. None of the research participants stated that the goal of making a profit was the primary goal of Mountain Jobs, and all participants pointed to the social goal of employing vulnerable populations as being an important goal, if not the more important goal of the enterprise.

Only the leadership staff indicated that profits from the enterprise were intended specifically to support Mountain Faith Coalition. Heidi and Robert both pointed to the "bootstrapping" nature of the enterprise - to keep costs low and become economically profitable as quickly as possible. The enterprise has controlled its costs by applying for grants and seeking community donations. By doing so, the staff may ensure that they have the tools to reach additional clients, generate additional income, and hire additional employees so that they may pay back investors. 
Mountain Jobs does have growth plans in the coming years to expand its profit base.

Heidi, Robert, and Aaron all indicated that they see the enterprise as remaining sustainable in the community. Growth plans include expanding the Work It Team's client base and working with additional businesses in order to form long-term partnerships with Mountain Jobs. Robert described growth plans, stating

But, I think absolutely yes, it is sustainable. And not just sustainable, but I think as it grow its going to grow, you know, we're going to have the staffing side of things, which is really going to start growing because Heidi hasn't been able to focus on it really yet, and we have the Get it Done Crew, which is going to start growing. But the ways that it's going to grow are really in these niche specialized areas that are ready to grow. Like for next summer, actually for this winter moving into next summer, we want to start a basically a full service lawn crew that will just do lawns, and then in the winter time they'll do like snow plowing stuff.

Additionally, Robert indicated that grants, as well as donations, are continually being researched and accepted.

\section{Social goal.}

Mountain Jobs has partnerships with Mountain Faith Coalition and other organizations in town. It connects employees to housing advocates through Mountain Faith Coalition, as well as puts them on the waiting list for shelter if they are not already sheltered. Heidi and Robert also discussed partnerships with other organizations in the community for assistance with child care and rehabilitation. This established pipeline allows Mountain Jobs to look at the life of each employee holistically in terms of ensuring they are connected to housing, childcare, transportation, and employment resources, while not seeking to serve as social workers and employers at the same time.

One of the most common themes throughout the interviews was the understanding nature of leadership at the social enterprise, specifically on the part of Heidi as being understanding of individuals struggling with transportation to and from work, scheduling concerns, or being 
willing to listen to a person's life situation. The theme of the understanding nature of the enterprise leadership staff arose in every interview. The most common theme in terms of the understanding nature of enterprise leadership is being flexible in terms of transportation, whether that is providing a ride or flexing an employee's schedule. Heidi, Robert, and Aaron indicated a willingness to assist employees with transportation, and personally drive them or provide them with a ride to work if necessary. The word "understanding" was used to describe Heidi by almost every participant. Carly explained, "Like, if I have my problems I can sit there and talk to the director. They get to know you more on a personal basis so they can sit there and connect with you."

Socially, enterprise leadership staff also focused on their role as an advocate for employees to find employment in addition to promoting the development of social skills to aid them in other jobs. Heidi used the word "advocate" five times in her interview to describe Mountain Jobs' role in finding employment for individuals experiencing homelessness. Additionally, Heidi, Robert, and Aaron distinguished Mountain Jobs from other employment agencies. Rather than focusing on a profit and ensuring as many people as possible are employed, they seek to work with each individual, find tools to assist them, and tell their story to each and every employer.

\section{Community Resources}

The community in which Mountain Jobs is located had existing social services and infrastructure prior to Mountain Jobs' existence. Existing social services includes a parenting center that provides free parenting resources and respite care for parents, an emergency homeless shelter for homeless individuals, and Mountain Faith Coalition services, which include housing advocates and a family shelter. Participants frequently noted that they rely on free public 
transportation in town to arrive at their jobs. If a job is outside of the boundaries of public transportation, or if public transportation is not timely, the social enterprise will then assist employees with transportation to a job.

Enterprise leadership staff are able to connect employees to social supports throughout the community and through their affiliation with their parent organization, Mountain Faith Coalition. A common theme was employee participants indicating that they utilize or were connected with social services through Mountain Faith Coalition, and enterprise leadership participants indicated that they or the enterprise connects individuals to outside social services, especially Mountain Faith Coalition services.

Finally, enterprise leadership staff participants indicated the importance of the community being aware of the mission of the social enterprise, and also understanding the difficulties individuals experiencing homelessness face in finding employment. Robert explained that faith communities that already support Mountain Faith Coalition were some of the first clients and advocates of the enterprise, and Heidi and Aaron explained that each time an organization hires an employee, the message is spread about Mountain Jobs and helps to connect the community. Robert explained,

It [Mountain Jobs] has this kind of exciting buzz. Especially this Work It Team has this cool factor in town because it's a social enterprise. And, social enterprises are a little newer around here. Just the concept of oh, it's a for-profit, and it helps people, and all the money goes to Mountain Faith Coalition. So, it has that kind of cool factor still.

Successes and Struggles with Employing Individuals Experiencing Homelessness

A success of employing individuals experiencing homelessness stated by both enterprise leadership staff and employees is increasing social skills for employees. This comes in the form of increasing soft skills, such as arriving to work on time and giving a person experience working with diverse types of people. Enterprise leadership staff indicated a lack of social skills 
in some employees due to mental illness, feelings of loneliness, or addictions. However, they explained that through social enterprise employment, the social skills of employees improved in terms of their ability to effectively communicate with others and mitigate conflicts. Employees indicated that their social skills were improved through interacting with clients and solving conflicts constructively with co-workers. When asked the question, "What skills do you think you have gained while working at Mountain Jobs," Carly explained, "It's helped me a lot with my communication and customer service skills.” Both Carly and Heather were formerly employed in telephone customer service positions and manual labor positions with limited contact with customers. With their work at Mountain Jobs involving housekeeping in homes or hotels, both Carly and Heather regularly communicate with co-workers and customers, which they indicate has improved their ability to communicate with others and interpret non-verbal cues from customers.

One of the struggles for employers in terms of employing the homeless come in the form of high turn-over rates. All three enterprise leaders mentioned the high volume of turn-over the enterprise faces, and this is attributed to the housing situation of employees. Additionally, upon beginning this research, one of the sampling criteria was that every participant had worked at the enterprise for at least eight weeks prior to being interviewed; however, due to turn-over among the managers of the Work It Team, the longest-employed manager was in the position for a total of three weeks. Heidi explained, "Yeah it's so fluid. I cannot emphasize that enough. For example, if they walk off a job or if they get fired from a job we can't work with them anymore; it's in our contract." Heidi also explained, "Yeah, but then we also have like four people a week quit or get hired by someone else so its super hard to track where they're going. Yeah, but in its entirety I just look at the content of our payroll scale and the numbers." Turn-over was an 
especially common theme that Heidi discussed in her interview when describing the struggles of employing individuals experiencing homelessness.

An additional struggle that employers face when employing individuals experiencing homelessness is employees who struggle with addiction or mental illness. Two employees, Don and Kurt, self-reported a former alcohol addiction, and these same employees self-reported struggles with mental illness in the past. Both employees indicated difficulties in staying positive in their outlook and situation of homelessness due to previous mental illness. However, they both explained that the understanding nature of the leadership staff of Mountain Jobs helps them to have a more positive outlook. One of the former managers of the Work It Team began as a crew member and was promoted to manager. Robert explained, "We had a crew lead that we kind of tried to help and had his own direct experience with homelessness, and he just, he kind of self-imploded a little bit," showing the difficulty that an employee experienced with balancing increased work responsibilities and mental health concerns. Heidi also explained, There was a person that was just doing awesome. There's a lot of folks who in this program are in different phases of recovery. Some of them have had 17 years, some of them have had 5, one of the gals just made her 2 year mark, but the folks who are in their transitionary phase of 2 weeks, 4 weeks, for example, I just got a message this morning for the person I have been working with who is wonderful, who has a lot of struggles with substance abuse. Um, when he's clean, and honest, and sober, he's just a great worker, he's got a really great outlook. But, he fell out of the wheelhouse and then I got a message this morning, he's in a halfway house, so that says to me that something had happened, which is worrisome, you know. So, that's a struggle that we encounter a lot.

\section{Successes and Struggles of Homeless Employees}

A success for homeless employees is an increased feeling of usefulness, and struggles include finding permanent housing, in addition to a lack of job training. For employees experiencing homelessness, employment brings feelings of self-fulfillment in the form of feeling useful or needed. Several times during his interview, Aaron emphasized the increased feelings 
of utility employees experience. He explained that homelessness is lonely, and being able to become a "productive member of society" boosts the self-esteem of employees. Participants commonly indicated increases in confidence or contentment in life as a result of feeling useful through their work. Aaron also remarked, "I would say that we make people who are not being currently utilized within a community; we're helping them to realize their potential as assets."

A struggle employees face is finding permanent housing once they are employed fulltime due to high housing costs or limited time availability because of their new jobs. Heidi, Robert, and Aaron indicated that high housing costs and a lack of available housing are challenging for employees, and Heather and Kurt indicated this as well. A common observation noted by employee and leadership participants was the difficulty in finding energy or time to find housing while adjusting to full-time work. Kurt indicated challenges finding housing due to possible discrimination based on his prior court record.

An additional struggle for employees is a lack of on the job training. Because the social enterprise has been working on making itself sustainable, a formalized job training system has not been established. All employees indicated coming in with prior job skills, such as mechanical, secretarial, or people skills. Additionally, participants indicated that all job training occurred on the job as necessary, but there is not a formalized program. While all employees did indicate a desire for additional training, none of them indicated that a lack of formal training negatively impacted their employment. Heather, Kurt, and Don indicated an interest in furthering their education at the local community college, and Kurt and Don indicated a desire to open their own businesses one day, but believed they needed additional training to do so. They hope to open businesses in roofing and auto mechanics, respectively. They believe they have the physical skills but could use additional skills, such as learning how to bid on projects or 
complete supply orders. Both Don and Kurt also indicated a desire to have a more centralized form of communication with the Work It Team, such as weekly meetings, to make sure everyone is on the same page with projects. For example, when asked if the Work It Team has any ongoing meetings, Don responded, "Not really. It would probably be a good idea if they did for the ones who actually do the moving, and that would be a little more helpful in that. Heidi calls us and it's like okay, what did she tell you, this is what she told me, okay, so read between the lines." Don indicated a desire for routine communication from enterprise staff, which Robert explained has not been a primary focus for staff as they have been working to establish the enterprise over the past year.

\section{DISCUSSION AND CONCLUSIONS}

The first research question addressed in this study is "Do employers provide opportunities for increasing levels of affiliation while employing individuals experiencing homelessness?" (A summary of the results of this study are depicted in Figure 1). Leadership staff engage in bonding social capital with employees by explaining their shared experiences with employees. Bonding social capital occurs when individuals are connected to others and share resources within their own social groups, such as when employees feel a sense of connection with co-workers or with enterprise leadership staff members due to shared experiences (Putnam 2000; Barman-Adhikari and Rice 2015). This was an especially common theme when employees discussed their sense of connection with Heidi due to her previous experience having difficulty obtaining employment and being a single mother. Heidi, Robert, and Aaron bridge social capital between employees and community members, social service agencies, and employers. Recall that bridging social capital occurs when an individual receives resources or connections outside of their own social network (Putnam 2000). Heidi, Robert, and 
Aaron each have a personal connection to the mission of Mountain Jobs, and they each started their positions with already established community connections through previous employment or life experiences, in addition to being connected to the congregation network affiliated with Mountain Faith Coalition, which is the beneficiary of Mountain Jobs. Recall that each leadership staff member earned at least a college degree and has previously established community connections. As a result, previous research suggesting that individuals who have attained higher education and are housed benefit from higher levels of affiliation that do those who did not attain higher levels of education and are not housed, is supported in this case (Cherlin 2014; Desmond 2014; Putnam 1993).

The next research question, "What impact does employment have on the levels of affiliation of an individual experiencing homelessness," yielded results that indicated that employees at the social enterprise experienced an increase in the number of affiliations they had with future employers, co-workers, and clients due to the bonding and bridging social capital work of enterprise leadership staff. Previous studies have suggested that increasing the variety and types of affiliations an individual has in their network, including having family and friends who are housed, connections with social workers, or connections with employers, prevents or ends homelessness for individuals (Barman-Adhakari et al. 2016). Employees indicated that they experience increased affiliation through bonding social capital when they are able to relate to the experiences of enterprise leadership staff. Therefore, it could be beneficial for current and future employees for the enterprise staff to hire employees experiencing homelessness in social enterprise leadership positions in the future.

Rather than being connected to their actual job at the enterprise, employees expressed a connection to one particular leadership staff member - Heidi, the executive director. Due to a 
lack of affiliation with housed family and friends, homeless employees expressed a feeling of trust with Heidi for several reasons, such as her understanding nature, relating to her experience as a single parent, or her own difficulty in seeking employment in the past. Considering that all employees expressed a personal connection with the enterprise director, this study suggests that the relationship between enterprise leadership and employees is important to employees. This is an example of bonding social capital because employees feel connected to the enterprise director based on similar experiences, increasing employees' trust in her. Typically, bonding social capital is thought to occur between individuals in a similar social class. While Heidi is in a different socioeconomic class than that of the employees she works with currently due to her enterprise employment, she is a positive affiliation for employees because she is able to connect them to employers and social services, but is also able to relate to them and understand their experience in unemployment or parenthood, having experienced both herself. Previous researchers have suggested that individuals experiencing homelessness are often disconnected from housed family and friends, but may have a network of homeless friends out of necessity of survival (Duneier 1999; Jencks 1995; LaGory 2010; Snow and Anderson 1993; Stack 1974). By building a relationship with Heidi, employees are increasing their affiliation with a person who they can trust, but who will also aid them in avoiding or escaping homelessness, resulting in a positive affiliation.

Previous research has suggested that the longer a person experiences homelessness, the more difficult it is for them to exit homelessness due to the sense of responsibility they feel in providing for others in the homeless community and connecting their friends with employment (Lee et al. 2010; Snow and Anderson 1993; Stack 1974; Venkatesh 2006). Due to the employment agency mentality of this social enterprise, employees are able to refer their friends 
to the social enterprise for employment opportunities, and Heidi will seek employment for them. Heidi is bridging social capital by facilitating a connection between a homeless employee and an employer. Despite their prior limited family and friend affiliations, employees are experiencing a net gain in affiliations as they maintain their pre-established friend and family relationships and gain relationships with social enterprise leadership staff, co-workers, and social service agencies.

"Social isolation," has been suggested as a cause of homelessness (Royce 2015:17;

Stovall \& Flaherty 1994). Because enterprise staff connects employees to employers and social service resources, and employees feel connected to other employees and leadership staff while also being able to refer their family and friends to Mountain Jobs, the risk of social isolation is decreased for employees through enterprise employment. Further, it has been suggested that by working with a social worker, individuals experiencing homelessness are ostracized by their homeless peers (Snow and Anderson 1993). However, because Heidi will find a job for anyone who is seeking employment, employees did not mention being treated with contempt by their homeless counterparts for working with Heidi or utilizing social services. Additionally, considering the theory of "cooperative poverty networks," in which individuals living in poverty rely on one another to obtain basic needs, making the cycle of poverty difficult to escape, being able to refer friends and family to Mountain Jobs will allow employees to keep the money they are earning when their friends and family living in poverty are also able to earn a paycheck through Mountain Jobs, providing a hope that the entire network will be able to increase their socioeconomic position (Stack 1973:24)

The question, "How do employers balance social objectives with economic objectives while employing individuals experiencing homelessness," was answered by asking employees and leadership staff members about the social and economic goals of the enterprise. Staff 
members balance both social and economic objectives by partnering with social service agencies to provide social support and by providing an understanding environment for employees. The economic objective of providing a source of income for Mountain Faith Coalition was mentioned as being important by all three enterprise leadership staff, but was not noted as the most important goal of the enterprise by anyone. Dart (2004) notes that as non-profits begin to establish profit-generating businesses, they should be careful to distinguish their profitgenerating activities from their non-profit mission. Mountain Faith Coalition created Mountain Jobs as a benefit corporation separate from Mountain Faith Coalition to distinguish their activities. Mountain Faith Coalition continues to maintain this distinction by employing an executive director, Heidi, of Mountain Jobs apart from the supervisor, Robert, of Mountain Faith Coalition as a whole. By distinguishing the social enterprise from the agency, a social service pipeline is created, which, in turn, creates a network of support for employees as suggested by previous research. Whiting (1994) suggests that employers should focus on the business goals of their enterprise and refer out for social services, which Heidi actively does as the executive director of this enterprise.

A common theme employed to describe the environment and staff of the social enterprise in relation to its sense of balance between social and economic objectives is the understanding nature of staff members, especially when describing Heidi. The leadership staff establishes an understanding environment by connecting employees to social service resources, such as housing advocates or parenting respite care at local agencies, and by assisting with transportation beyond the scope of the free public transportation system. The enterprise leadership staff also strives to know the story of each individual employee and connects them with the resources they need to be successful in their job. Unlike previous research, which has indicated that non-profits that 
add a for-profit business component to their activity tend to focus too much on making money and not enough on the social needs of homeless employees, this social enterprise provides a “strong culture" of understanding for employees. (Dart 2004; Leadbeater 2013; Whiting 1994:29).

Recall that the next research question is, "What resources do communities have in place that support a business with a goal of employing the homeless?" Enterprise leadership staff members and employees indicated the importance of the free public transportation system for employees. A lack of transportation is a factor leading to social isolation among the homeless, making it difficult for individuals to access work or remain connected with housed family and friends, so this community helps to reduce the barrier of transportation by making it free to all citizens (Burt 1992; Royce 2015). Prior to the establishment of Mountain Jobs, the community already had a family homeless shelter and housing advocate network through Mountain Faith Coalition, an emergency shelter for individuals experiencing homelessness, and parenting resources through a partner agency. The pre-existing social service agencies provide services for employees, who are referred to them through Mountain Jobs. Additionally, Mountain Faith Coalition has a network of congregations that it partners with, and which provided some of the first clients of Mountain Jobs and the Work It Team's services.

The fifth research question, "Practically, what are the struggles and successes with employing individuals experiencing homelessness," yielded responses including high turn-over rates and employees facing mental illness concerns. Previous research suggests that promoting an environment of support and understanding for homeless employees that struggle with mental illness, as this social enterprise does, is a best practice (Leadbeater 2013; Teasdale 2009; Whiting 1994). A success noted by the enterprise leadership staff members when employing individuals 
experiencing homelessness is noticing an improvement in employees' social skills. Many employees previously worked in positions with limited human contact or have had difficulty communicating due to mental illness. Due to their contact with co-workers and clients on a daily basis through their work, employees and employers both noted an improvement in employees' social skills.

The final research question also explored successes and struggles for employees experiencing homelessness by asking, "What are the struggles and successes that an individual experiencing homelessness faces while working at an enterprise with the goal of employing the homeless?" A success for employees was increasing their sense of feeling useful. The successes that employees face in terms of increasing social skills (identified by both leadership staff and employees) and increased feelings of utility are consistent with Whiting's (1994) findings that employment for homeless populations increases self-esteem for employees.

Struggles employees face include obtaining permanent housing and not receiving formalized job training. While all employees indicated satisfaction with their work, they also indicated a desire for further job training opportunities. Collins (2016) found that to prevent individuals experiencing homelessness from becoming stagnant in low-paying jobs over the long term enterprises that employ the homeless can offer formal opportunities to network with companies in high-paying sectors and also provide training in technology. Both Whiting (1994) and Teasdale (2009) suggest a formalized job training component for social enterprises, which employees also indicate an interest in throughout this study. Pairing a job training component with suggestions from employees, in addition to the understanding nature of the enterprise, would satisfy employees' requests for training, especially in terms of bidding on jobs and ordering supplies. 
Partnerships with a local community college or networking opportunities beyond client interactions could assist in further increasing the number of affiliations employees at this enterprise gain. Venkatesh (2006) explains that individuals living in poverty have difficulties finding work in the mainstream economy, and instead, turn to the underground economy for work. All of the employees indicate high turn-over in previous jobs. The primary jobs available through Mountain Jobs and the Work It Team in the service or manual labor sectors will keep employees in low-paying jobs until they receive additional job training or attain higher education, which is why previous studies have suggested job training options for employees experiencing homelessness (Collins 2016).

An additional struggle employees experiencing homelessness indicated facing is difficulty finding housing due to high housing prices, a lack of time once they obtain full-time employment, or a previous criminal record. Throughout the Western United States, housing prices are rising, the availability of rentals is decreasing, and in many places, wages are remaining stagnant (Rosenberg 2017). These three factors contribute to longer periods of homelessness and increasing numbers of individuals experiencing homelessness. Perhaps a future affiliation that leadership staff could seek is establishing a relationship with a landlord in the community who would assist enterprise employees in obtaining permanent housing.

Increasing the number and types of affiliations individuals have has been suggested as being more important than is level of educational attainment in order to assist them in ending or avoiding homelessness (LaGory 1990). While the employee participants in the current study were homeless, each employee was experiencing an increase in affiliations, while maintaining their (limited) pre-existing relationships. The current study demonstrates that by increasing their affiliations through both bonding and bridging social capital, employees were able to gain access 
to employers, social services, and foster relationships with other employees and staff members, while also generating an income, developing social skills, and increasing their feelings of utility. In increasing their affiliations, employees are diversifying their networks and creating a foundation of resources to utilize as they seek permanent housing or if they are at risk of becoming homeless in the future.

\section{Limitations and Implications for Future Research}

This research is limited in its scope, generalizability, and sample size. This is a case study of one social enterprise in one mid-sized city, so the results are not generalizable to every community or every social enterprise. However, the results of this study may be employed as a foundation for individuals looking to expand or create a social enterprise that focuses on employing the homeless in other mid-sized cities in the Western United States. Additionally, future research could examine social enterprises that employ individuals experiencing homeless in larger and smaller cities, or examine other models of social enterprises. For example, future researchers could conduct studies on shelters that employ residents, social enterprises that specifically offer job training but do not pay participants, or stand-alone social enterprises that are not affiliated with a non-profit agency (Teasdale 2010).

Future research could also include a non-participant observation component if a standalone social enterprise is studied in public area, such as a coffee shop or thrift store. Because the Mountain Jobs offices are simply a space for employees to be interviewed or receive paychecks and then be sent out to work in client's homes or businesses, there was not a public place to conduct non-participant observation in this study. Additionally, this social enterprise had been open for about one year at the time of the study. Therefore, leadership staff are still determining what is effective in terms of operations, staff, and procedures. Future research could examine 
social enterprises that employ the homeless in their initial conception and also enterprises that have been established for longer than one year, which would also add to this body of research. Social enterprises could also be studied that specifically employ one population of individuals experiencing homelessness, such as women or veterans, to determine the effects of employment on specific populations.

One final limitation of this research is the sample size. Additional research could look to interview board members, homeless service providers in town, or additional employees. At the time of the current study, four out of the five employees of Mountain Jobs who were experiencing homelessness were interviewed (one declined participation); however, housed employees could be interviewed in a different study. Additionally, due to time constraints, all board members were not interviewed and additional homeless service providers were not asked to participate due to the focus of the current research on one social enterprise. Future researchers could also look to compare two social enterprises that employ the homeless and interview employees at both enterprises to determine best practices for employers, as well as look for patterns in successes and struggles for employees and employers. Additionally, recall that loneliness is often associated with homelessness. Future research could explore whether the relationships gained are just as important as the services received, as the employees interviewed in this study emphasized their connections with Heidi even more so than the jobs they held. Despite these limitations, the current research contributes to our current state of knowledge concerning affiliation theory and the employment of the homeless by social enterprises in several ways. First, the current study assists in determining the importance of bonding and bridging social capital between employees and employers, other employees, and social service agencies. Second, this research highlights how social enterprises may balance social and economic 
objectives in serving the homeless population. Third, this study contributes to our understanding of the importance of local community resources in assisting the homeless in transitioning to selfsufficiency. Finally, the successes and struggles associated with employing the homeless, and associated with employment among the homeless, are explored. As a result, the current study provides an important foundation for future studies on how social enterprises and the communities in which they are located may assist vulnerable populations more generally 
Table 1: Employee Demographic Information

\begin{tabular}{|c|c|c|c|c|c|c|c|c|}
\hline Name & Gender & $\begin{array}{c}\text { Marital } \\
\text { Status }\end{array}$ & $\begin{array}{c}\text { Length of } \\
\text { current } \\
\text { homelessness }\end{array}$ & $\begin{array}{c}\text { Number of } \\
\text { times of } \\
\text { homelessness } \\
\text { over lifetime }\end{array}$ & $\begin{array}{l}\text { Highest } \\
\text { level of } \\
\text { education } \\
\text { (number of } \\
\text { education) }\end{array}$ & $\begin{array}{c}\text { Children } \\
- \text { Yes or } \\
\text { No }\end{array}$ & $\begin{array}{c}\text { Living } \\
\text { situation }\end{array}$ & $\begin{array}{c}\text { Previous } \\
\text { Court } \\
\text { Record - } \\
\text { Yes or } \\
\text { No }\end{array}$ \\
\hline Don & Male & $\begin{array}{l}\text { In a } \\
\text { relationship }\end{array}$ & Three months & Six & G.E.D. & Yes & $\begin{array}{l}\text { Lives in } \\
\text { Mountain } \\
\text { Faith } \\
\text { Coalition } \\
\text { shelter }\end{array}$ & Yes \\
\hline Kurt & Male & Single & Unanswered & At least 14 & $\begin{array}{l}\text { Associates } \\
\text { Degree }\end{array}$ & Yes & $\begin{array}{c}\text { Lives in a } \\
\text { local shelter } \\
\text { for individuals } \\
\text { experiencing } \\
\text { homelessness }\end{array}$ & Yes \\
\hline Heather & Female & $\begin{array}{c}\text { Single } \\
\text { (divorced) }\end{array}$ & Eight months & One & $\begin{array}{c}\text { Some } \\
\text { college }\end{array}$ & Yes & $\begin{array}{l}\text { Lives in } \\
\text { Mountain } \\
\text { Faith } \\
\text { Coalition } \\
\text { shelter }\end{array}$ & No \\
\hline Carly & Female & Married & Three months & Two & $\begin{array}{l}\text { Associates } \\
\text { Degree }\end{array}$ & Yes & $\begin{array}{l}\text { Coach/hotel } \\
\text { surfing (on the } \\
\text { waiting list for } \\
\text { Mountain } \\
\text { Faith } \\
\text { Coalition } \\
\text { Shelter) } \\
\end{array}$ & Yes \\
\hline
\end{tabular}


Table 2: Leadership Staff Demographic Information

\begin{tabular}{|c|c|c|c|c|c|c|}
\hline Name & Job Title & Gender & $\begin{array}{c}\text { Personal } \\
\text { experience } \\
\text { with } \\
\text { homelessness } \\
- \text { Yes or No }\end{array}$ & $\begin{array}{c}\text { Highest } \\
\text { Level of } \\
\text { Education }\end{array}$ & Marital Status & $\begin{array}{c}\text { Children - } \\
\text { Yes or No }\end{array}$ \\
\hline Heidi & $\begin{array}{c}\text { Executive } \\
\text { Director }\end{array}$ & Female & No & $\begin{array}{c}\text { Master's } \\
\text { Degree }\end{array}$ & $\begin{array}{c}\text { In a } \\
\text { relationship }\end{array}$ & Yes \\
& $\begin{array}{c}\text { Manager } \\
- \text { Work It } \\
\text { Team }\end{array}$ & Male & Yes & $\begin{array}{c}\text { Bachelor's } \\
\text { Degree } \\
\text { (divorced) }\end{array}$ & Yes \\
\hline Robert & $\begin{array}{c}\text { Manager, } \\
\text { Mountain } \\
\text { Jobs; } \\
\text { Director, } \\
\text { Mountain } \\
\text { Faith } \\
\text { Coalition }\end{array}$ & Male & No & $\begin{array}{c}\text { Master's } \\
\text { Degree }\end{array}$ & Married & Yes \\
\hline
\end{tabular}




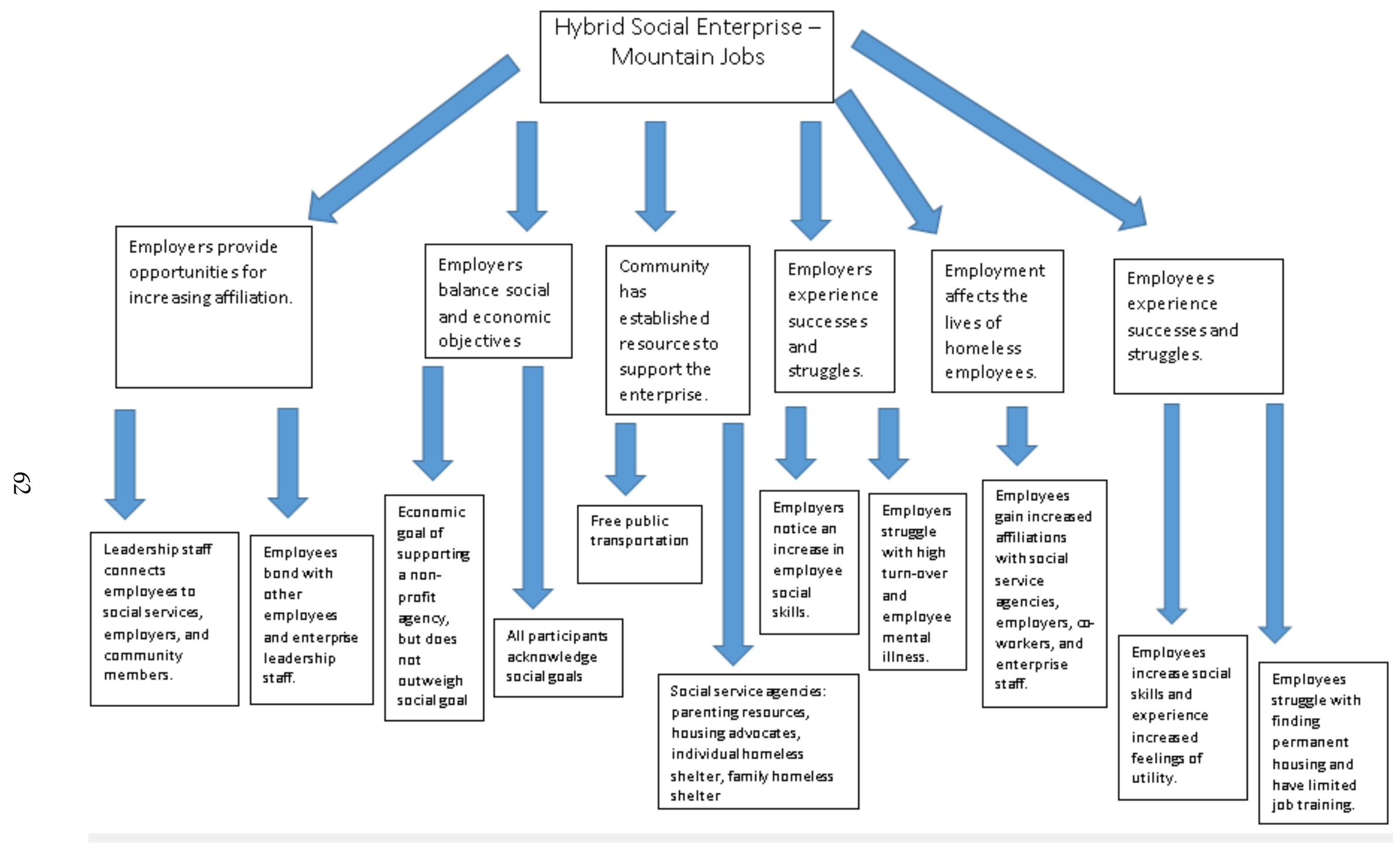

Figure 1: Results Summary 


\section{CHAPTER II: HOMELESSNESS IN THE UNITED STATES}

\section{INTRODUCTION}

The federal definition of homelessness and societal perceptions of homelessness have changed over time (Jencks 1995; Royce 2015). In the 1920s the homeless were either "the hobo," "the tramp," or "the bum," who were white men living on the streets or in homeless camps (Anderson 1961:61). By the 1980s, the homeless were classified as individuals who resided in emergency shelters (Jencks 1995; Rossi 1991). Single, white men became the "old homeless," whereas families, women, and minorities became the "new homeless"

(Burt 1992; Rossi 1991; Shlay and Rossi 1992:130-132). In 1987, the federal government passed the McKinney-Vento Act, which defined homeless individuals as lacking a place to stay at night and described a difference between the sheltered and unsheltered homeless (Lee, Tyler, and Wright 2010; Rossi 1991). Most recently, the U.S. Department of Housing and Urban Development defined an individual experiencing homelessness as a person who is living somewhere where humans should not live, such as an emergency shelter, transitional housing unit, or unit they are at risk of losing. Additionally, individuals who are leaving domestic violence situations and do not have anywhere else to live are considered homeless (National Alliance to End Homelessness 2012).

2017 was the first year since 2010 that the number of individuals experiencing homelessness increased in the United States since (HUD 2017). Approximately 3.5 million individuals experience homelessness each year; however, this number varies due to changing definitions of homelessness (National Coalition for the Homeless n.d; Phillips 2015). As a result of these changing definitions, estimates of the number of individuals experiencing homelessness each year ranged from 250,000 people per year to nearly 3,000,000 individuals per year in the 
1990s depending on the definition being used. To obtain a more accurate estimate of the number of individuals experiencing homeless, and in collaboration with social service providers, a pointin-time count was created in 2005 to be conducted each January in cities throughout the United States. The purpose was to determine a count of the sheltered and unsheltered homeless population (National Alliance to End Homelessness 2012). Because the count occurs on only one night each year and due to gaps in knowledge of the locations of the unsheltered homeless, as well as the hidden nature of those living in cars or doubled up, the accuracy of this count has been questioned (Dear and Wolch 1987; Jencks 1995; Lee et al. 2010; National Alliance to End Homelessness 2016; Shlay and Rossi 1992).

As homelessness became recognized as a social problem in the 1980s, state, federal, and local governments began proposing solutions to eliminating homelessness. The McKinneyVento Act (1987) mandated Continuums of Care in communities, which allows communities to apply for federal funding to coordinate non-profit and government services to the homeless to ensure that the spectrum of needs of the homeless are being met (Lee et al. 2010). Other solutions have included both federal and local governments creating yearly plans to end homelessness, increased funding for emergency shelters, as well as the creation of employment programs for the homeless (Blau 1985; Desmond 2014; Jencks 1995; Lee et al. 2010; Lei 2013; U.S. Conference of Mayors 2016; Wright 2009). Other localities have made efforts to decrease the visibility of homelessness in their communities by stigmatizing those asking for money through anti-panhandling laws (Lankenau 1999; National Law Center on Homelessness \& Poverty 2015; Rayburn and Guittar 2013). Perceptions of the homeless, especially the visible homeless, such as those who are asking for money, range from individuals with higher levels of education attributing homelessness to structural factors to those with lower levels of education or 
less contact with the homeless attributing homelessness to individual factors, such as laziness (Goffman 1963; Lankenau 1999; Lee et al. 1990; Phillips 2015; Snow and Anderson 1993). Previous research has addressed the history of homelessness in the United States in terms of causes, solutions, and definitions; however, there is a gap in the literature on perceptions of the homeless and strategies for educating the general public about homelessness (Anderson 1961; Blau 1985; Burt 1992; Desmond 2014; Jencks 1995; Lee et al. 2010; Phillips 2015; Rossi 1991). Additionally, previous research has examined programs that have been created for specific populations of the homeless, such as homeless veterans or the mentally ill, but there has been a limited amount of scholarship beyond these studies that addresses specific employment programs for the homeless, despite such programs being identified by the homeless as a need (Lam and Rosenheck 2000; Marrone 2005). This literature review looks to the work of stratification theorists Marx (1867/2001), Weber (1914/1948/1982), Royce (2015), Khan (2011), and Sewell et al. (1867/2001) and presents demographic information regarding who is homeless in the United States. The present study also addresses structural causes of homelessness, including a lack of affordable housing, unequal access in education, and limited job availability to contribute to the literature on causes and responses to homelessness in the United States. Perceptions of the homeless, and responses to homelessness at both the federal and local levels within a social stratification framework, are also presented.

\section{MOTIVATION/SIGNIFICANCE}

The motivation for this research comes from both my experience conducting research on the self-identified needs of the urban homeless in Grand Rapids, Michigan in 2013 and from Sudhir Venkatesh's (2006) ethnography, Off the Books, The Underground Economy of the Urban Poor. My 2013 research involved participant observation at social service agencies that provide 
services to the homeless in Grand Rapids, Michigan. Throughout my time volunteering at agencies and through informal conversations with homeless clients, I learned that many of the individuals experiencing homelessness had a desire to work but faced barriers to obtaining employment, such as a lack of transportation, expensive child care, or a lack of work experience. Additionally, as Lei (2013) explains, simply being identified as homeless can be a barrier to employment due to limited internet or phone access, not having a permanent address, and sometimes facing mental illness or substance abuse concerns

Unemployment is a cause of homelessness (Shlay and Rossi 1992). Unemployment is perpetuated, especially among those with lower levels of education or living in low-income areas, due to a lack of job availability or availability of primarily service jobs that pay low wages (Mishel et al. 2012). As a result, individuals experiencing homelessness turn to day labor, which is temporary work that generally pays the minimum wage or just above it and lasts only temporarily, or choose to participate in the underground economy (Lei 2013; Venkatesh 2006). Consistent with my participant observation research, previous studies have shown that individuals experiencing homelessness have a desire to work, but face barriers in finding employment (Snow and Anderson 1993). Because of a desire to work among individuals experiencing homelessness but a lack of available jobs, there has been a call to focus studies on businesses and individuals that employ individuals experiencing homelessness. Additionally, there has been a gap in the research identified on determining whether social enterprises that focus on employing the homeless are helpful to homeless employees, what are the impacts of these enterprises on communities, and in determining how social enterprises center their businesses both socially and economically (Lei 2013; Teasdale 2010). Therefore, this project 
provides a way to examine the effects that employing individuals experiencing homelessness has on both employees and employers at a social enterprise.

\section{ADDITIONAL LITERATURE REVIEW}

\section{Stratification Theories on Homelessness and Poverty}

Individuals living in poverty are at risk of becoming homeless (Burt 1992; Desmond 2014). Stratification theorists, beginning with Marx (1867/2001) and Weber (1914/1946/1982), have discussed causes of poverty. Marx (1867/2001) discusses classes in the capitalist system composed of the workers (or what he referred to as the "proletariat") and the owners of the means of production (in Marx's terminology, the bourgeoisie). Within the proletariat class is the lumpenproletariat, who do not work and also do not own property. This class needs to be mobilized by others, according to Marx, to realize their similar depressed living situations and overthrow the bourgeoisie. Until the lumpenproletariat and proletariat class in general are organized, they will be continually oppressed by the bourgeoisie. Therefore, for Marx, homelessness would be a result of oppression from the bourgeoisie and a lack of class consciousness among the proletariat in terms of realizing similar goals and working together to achieve those goals $(1867 / 2001)$.

Weber (1914/1946/1982), too, discusses class consciousness, arguing that groups with the most power are those that recognize their collective interests and can effect change as a result of organizing. However, Weber explains that stratification is inevitable within society and argues that socioeconomic position is not based on income alone, but also on political power. Therefore, the homeless for Weber lack income, but also lack political power, and Weber would argue that the movement toward devoting fewer taxpayer dollars to public assistance is a reflection of the limited political power in the hands of the homeless (Mishel et al. 
2012). Gottschalk et al. (1994) expands on this, finding that conservatives believe reports on poverty are exaggerated. Given that conservatives currently control all three branches of the U.S. Government, it can be expected that public assistance dollars and legislation favorable to those living in poverty will not increase.

Sewell et al. (1969) reflected Weber's sentiment of stratification as being an inevitable aspect of society, suggesting that a father's job and education level does impact a child's (specifically a son's) education and future job, but also found that social psychological variables, such as amount of encouragement from others, goals, and academic performance also influenced status attainment for sons. Sewell et al. (1969) would argue that the homeless lack educational capital, encouragement from others, and have fathers who lack occupational and academic prestige as well. Therefore, it is difficult for children who have parents who live in poverty to leave poverty as adults. Education can help children escape poverty; however, seventy-four percent of smart children from wealthy families finish college, whereas only 29 percent of smart children from poor families finish college (Sewell et al. 1969).

For modern stratification theorists, poverty and homelessness are a result of structural deficiencies in understandings of poverty, a lack of aid, and a lack of employment. Mishel et al. (2012) explain that there has been a rise in low-paying service jobs recently, making it difficult for people to live on the meager wages they are receiving in these service jobs. Poverty is a "low priority problem" in the United States, and misunderstood as books such as the "The Bell Curve" have been released, attributing poverty to a low IQ score without considering structural factors, such as limited job availability and educational inequality (Hernstein and Murray 1994; Royce 2015:29). Additionally, racial discrimination, low minimum wages, and unfavorable public assistance reform have made it difficult for the poor to escape poverty, and puts them at 
continued risk of homelessness (Royce 2015). Therefore, while theorists such as Weber (1914/1946/1982) have explained homelessness and poverty as structurally inevitable, many contemporary theorists have addressed poverty and homelessness as a result of societal structure, government policies, and limited job availability (Royce 2015; Venkatesh 2006).

\section{Demographic Information}

On a given night in January 2017, men comprised 61 percent of individuals experiencing homelessness, whereas women accounted for 39 percent, and individuals who identified as transgender accounted for less than 1 percent of the homeless population. White individuals experiencing homelessness accounted for 47 percent of the homeless population, and individuals who were Black, Hispanic or Latino, or multiracial comprised 41 percent, 22 percent, and seven percent, respectively (The United States Department of Housing and Urban Development 2017).

The point-in-time count, conducted in cities each January, distinguishes between the sheltered and unsheltered homeless in the count. Those who are sheltered are living in an emergency shelter or transitional housing programs, whereas the unsheltered are those living on the streets or in public places (HUD 2017). Figure

I displays the percentages of individuals who were living in sheltered and unsheltered situations on a given night in 2017 , in addition to those who were members of families. The largest population of the homeless were sheltered individuals (35 percent), closely followed by sheltered members of families (30 percent) (HUD 2017:8).

Percent of Homeless People

By Household Type and Sheltered Status, 2017

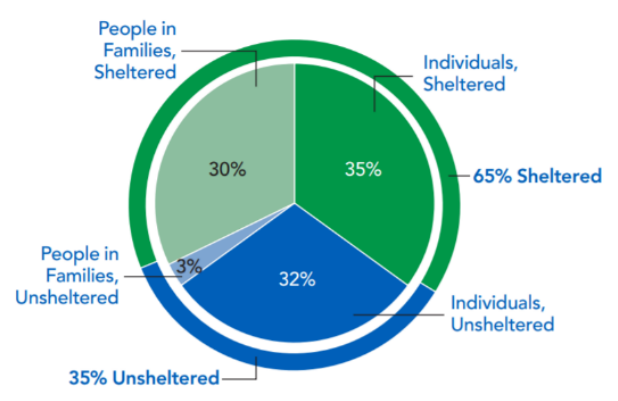

Figure 2: Sheltered and Unsheltered Homeless Individuals in 2017 
The United States Department of Housing and Urban Development (2016) has identified subpopulations of the homeless in their reports, including the chronically homeless, homeless families, veterans, and youth. Twenty-one percent of individuals experiencing homelessness on a given night in January 2017 were children under 18 years old, and 40,000 were veterans (2017:4). Additionally, 87,000 were chronically homeless, meaning individuals with persistent homelessness lasting at least one year or facing repeated periods of homelessness. Finally, there were 40,000 individuals identified as unaccompanied youth under the age of 24 . This is also reflected in HUD's strategic plan, as their federal-level goals to end homelessness, most recently, are to decrease veteran homelessness, decrease, prevent, and end family, youth, and childhood homelessness by 2020, and end "chronic homelessness," while also preventing homelessness for all populations (2017:4). Historically, since the 1980s, homeless families and women are two of the fastest growing populations of individuals experiencing homelessness (Jencks 1995; Lee et al. 2010; Rossi 1991).

\section{Causes of Homelessness}

Homelessness has been declining in the United States since 2009, but the number of individuals experiencing homelessness in 2017 increased from 2016. There was a 13 percent decrease in the number of individuals experiencing homelessness from 2010 to 2017, and a 24 percent decrease in the number of families experiencing homelessness from 2010 to 2017 (United States Conference of Mayors 2017:4). However, 3.5 million people still face homelessness each year in the United States (National Coalition for the Homeless 2009; Phillips 2015). Both macro and micro level causes of homelessness have been determined (Lee et al. 2010). Macro-level causes include poverty, a lack of affordable housing, unemployment, strict welfare requirements, and deinstitutionalization (Burt 1992; Desmond 2014; Jencks 1995; 
National Alliance to End Homelessness 2016; Rossi 1991; Snow and Anderson 1993). Microlevel causes include drug use, alcohol use, and dysfunctional family structures (Burt 1992;

Chamberlain and Mackenzie 2006; Jencks 1995; Lippert and Lee 2015).

Macro-level causes: poverty.

While the percentage of individuals experiencing homelessness has been on the decline since 2009 (despite the one percent increase in 2017), the number of people living in poverty is now greater than the number prior to the Great Recession, lasting from 2007 to 2009 (HUD 2017; National Alliance to End Homelessness 2016). Non-metropolitan areas are at a higher risk of having high poverty rates (more than 20 percent). One in five non-metropolitan areas have high poverty rates, while one in 20 areas that are considered metropolitan are high poverty areas (National Coalition for the Homeless n.d.). Burt (1992) argues that poverty increases a person's risk of becoming homeless more so than inequalities in education, access to social services, or discrimination based on race, gender or ethnicity. Poverty can lead to eviction, which is a strong predictor of homelessness (Desmond 2014).

Poverty is perpetuated in the United States by discrimination based on race and ethnicity (including unequal access to home loans), a lack of affordable housing, disparities in educational opportunities, and a lack of affordable public transportation (Royce 2015). Women, specifically single mothers and single mothers who are African American or Latina, are at the highest risk of poverty, and also at high risk of homelessness (Jencks 1995; Lee et al. 2010; Rossi 1991; Royce 2015). This has led to the United States being ranked first in child poverty among comparable developed countries, and the United States having higher poverty rates overall as compared to other developed nations (Cherlin 2014:8). As of 2016, the poverty rate in the United States was 12.7 percent, with the poverty rate for men being 11.3 percent and the rate for women being 14.0 
percent. Native Americans had the highest poverty rate of any racial/ethnic group at 26.2 percent, with African Americans following them at 22.0 percent (Semega et al. 2017).

\section{Lack of affordable housing.}

Beginning in the 1960s, cities began demolishing single resident occupancies (SROs) in an attempt to beautify cities. These SROs provided basic accommodations at affordable prices for those living in poverty and on the brink of homelessness. Cities justified tearing down SROs because at this time, government subsidies to the poor were increasing. This movement led to the elimination of 1.1 million affordable housing SROs between 1970 and 1982 (Jencks 1995:82). Throughout the 1980s, increased interest rates and difficulties in purchasing a home for first-time home buyers resulted in individuals and families continuing to rent their homes (Koegel, Burnam, and Baumohl 1996). Discrimination in housing has also pushed the poor into areas of high crime and pushed racial and ethnic minority groups into impoverished areas with limited resources at alarming rates (Burt 1992; Venkatesh 2006). From 2006 to 2010 approximately 8 million kids, most of them minorities, lived in neighborhoods in which at least 30 percent of the population was poor, limiting the resources these children have to escape poverty and homelessness themselves (Kids Count 2014 as cited in Royce 2015:204).

Inflation has led to an increase in housing costs. This, coupled with a decrease in jobs that pay livable wages, has caused many poor families to spend over half of their income on housing, when the standard is to devote 30 percent of a family's or individual's income to housing (Desmond 2014; Snow and Anderson 1993). High housing prices and decreases in available public housing have led to an increase in evictions in cities across the United States. In Milwaukee, Wisconsin alone, 16,000 people face eviction yearly in a city of 105,000 residents (Desmond 2014:4). Further, home foreclosures have increased since 2006 by 400 percent, and 
those living in poor neighborhoods with a racial minority population have been affected the most (Royce 2015:209). High housing prices, in addition to the cost of food, transportation, and childcare, make it difficult for the poor to save and work their way out of poverty, causing them to continually remain in precarious housing situations with the risk of becoming homeless (Royce 2015; Venkatesh 2006).

\section{Lack of employment opportunities.}

Reduced employment opportunities, increasing credential requirements for jobs, and low minimum wages have made it difficult for those who are currently homeless and those at risk of homelessness to find jobs (Anderson 1961; Blau 1985; Desmond 2014; Lee et al. 2010). Unemployment also leads to homelessness due to a lack of income to pay for housing over time (National Alliance to End Homelessness 2016). As of 2013, the wage required to rent a two-bedroom apartment nationally was $\$ 18.79$ per hour; however, the average individual tenant earns only $\$ 14.32$ per hour on average (National Coalition for the Homeless n.d.). This is not predicted to improve, as public funding for affordable housing creation is not increasing and the most prevalent jobs available are low-paying service sector jobs (Burt 1992; Mishel et al. 2012).

Those living in poverty and the homeless participate in the "underground economy" to find ways to support themselves (Venkatesh 2006:xii). This underground economy, also referred to as "shadow work," involves earning income that is not reported to the government through "licit" activities (baby-sitting, cooking food, etc.) or "illicit" activities (panhandling, prostitution, or drug dealing) (Snow and Anderson 1993:171; Venkatesh 2006). The underground economy is constantly changing and income is not stable; however, it does provide a temporary income for participants and can "help men to stabilize their lives" (Snow and Anderson 1993:171; 
Venkatesh 2006). Additionally, participating in the underground economy puts a participant at risk of receiving a criminal charge due to the illegal activities in which they participate, making it even more difficult for them to find a job in the future (Venkatesh 2006).

Panhandling and street vending have been studied in recent years as aspects of the underground economy. Panhandling involves asking for money, whereas street vending involves selling items not purchased by a vendor in public areas, such as on the sidewalk in front of stores. These options allow an individual who has a criminal record or experiences mental illness, as the homeless disproportionally do, to earn an income (Duneier 1999). However, as panhandling and the street economy become visible, cities adopt "broken window policies" that criminalize these activities, further increasing the difficulty of the homeless in eventually participating in the formal economy (Duneier 1999:226).

Welfare and public assistance.

A decline in public assistance and more stringent welfare requirements have been cited as causes of homelessness (National Coalition for the Homeless n.d.; Rossi 1991). During the 1980s, families that were receiving Aid to Families with Dependent Children through the federal government experienced a decline in aid, resulting in 800,000 people receiving reduced or no aid between 1980 and 1981 and taking nearly half a million people off Social Security Income Disability Insurance from 1981 to 1984 (Koegel et al. 1996:28). Beginning in 1992, states were able to apply to the federal government for "waivers" to decrease access to welfare reform within their states, making access to welfare difficult for those living in poverty (Greenberg and Baumohl 1996). Additionally, many forms of welfare require a working component, which is difficult for families with children, considering the burden of the cost of childcare (Jencks 
1995). The lack of availability of aid, along with strict requirements, cause homelessness and also make it difficult for individuals to exit homelessness.

Welfare in the United States that is available to the poor is often only available to those with children or those with disabilities (Toro et al. 2007). It has become increasingly difficult for single adults to receive public assistance, which contributes to homelessness, especially considering 50 percent of all adults experiencing homelessness receive less than $\$ 300$ in income per month (Burt 2001). The most common type of public assistance that people receive is food assistance; however, public assistance in the form of housing dollars has also been reduced (2001). Additionally, housing vouchers, another form of public assistance, help poor families to pay for rental housing costs greater than 30 percent of their income. This program, too, has seen decreased funding from the federal government, and the process to obtain a voucher can be long and competitive (National Alliance to End Homelessness 2016).

\section{Deinstitutionalization.}

Deinstitutionalization of those experiencing mental illness has been cited as an additional cause of homelessness (Blau 1985; Burt 1992; Jencks 1995). Deinstitutionalization occurred in three waves. The first wave, occurring in the 1950s, called for the removal from institutions those who could be treated for their mental health concerns as out-patients. The second wave, beginning around 1965, involved Medicaid paying only for short-term stays in institutions, rather than covering long-term treatments. The final wave in 1972 strongly urged moving people out of state institutions and decreased state tax dollar funding of institutions, which is the wave attributed with causing homelessness (Jencks 1995). By 1987, 1.7 million individuals could not hold a job due to mental illness, and 100,000 of those individuals were experiencing homelessness (Jencks 1995:38-39). Others have argued that the link between homelessness and 
deinstitutionalization is not as prominent as has been suggested (Rossi 1991; Snow and Anderson 1993). Instead, the focus is on the difficulty in obtaining Social Security Disability Insurance for those experiencing mental illness and the difficulty in holding a job, which causes homelessness (Rossi 1991).

Micro-Level Causes

Micro-level causes of homelessness attribute individual factors to causing homelessness. These views, for liberals, are rooted in sympathy, with liberals believing that life occurrences that are outside of the control of the individual cause homelessness; therefore, policy should focus on providing mental health services, job counseling, etc. to help the homeless with these circumstances (Koegel et al. 1996). For conservatives, homelessness is viewed as a result of individual choices at the micro level: the homeless are lazy, choose to make bad choices, or lack the ability to find a job or advocate for themselves (Koegel et al. 1996; Cherlin 2014).

\section{Drug and alcohol use.}

Before the 1980s, alcohol was a cheaper purchase for those experiencing homelessness than were drugs (Jencks 1995). However, with the availability and inexpensive cost of crack in the 1980s, its usage among those experiencing homelessness increased. In a 1991 study in New York City, 66 percent of single adults experiencing homelessness and living in shelters tested positive for the use of crack (Jencks 1995:42). While there is not a direct link between crack usage and homelessness, crack does impair a person's job search, which leads to alienation from family and friends and increases the chances of becoming involved in the criminal justice system (Burt 1992; Jencks 1995). While crack consumption has certainly made it difficult for users to hold and maintain jobs, thereby leading to homelessness, additional research is needed to 
determine whether crack use among the homeless begins prior to homelessness or after an episode of homelessness has begun (Jencks 1995; Lee et al. 2010). Additionally, selling crack is considered "shadow work," or an informal way of earning an income for those experiencing homelessness. Even among those individuals not using crack, it is a way to make money, which may lead to criminalization and subsequently make holding or finding a job difficult (Snow and Anderson 1993:171).

Traditionally, there have been three categories of the homeless: the chronically homeless, those experiencing episodic homelessness, and those experiencing transitional short-term homelessness (National Coalition for the Homeless n.d.). However, a new system of categorization has been suggested: the homeless are individuals living on the street, those who chronically consume alcohol, those with long-term mental illness, and/or those experiencing short-term episodic homelessness (Jencks 1995). Like drug use, there is no direct connection between alcohol use and becoming homeless; however, alcoholism does have an impact on job search and retention, which can lead to homelessness or cause a person to remain homeless (1995). Additionally, alcohol and drug usage can lead to "dysfunctional family structures," such as divorce, domestic violence, or spousal distress, which is another cause of homelessness (Lippert and Lee 2015; Moss 2015:22).

\section{Dysfunctional family structures.}

Jencks (1995) notes that while there has been speculation that dysfunctional family structures, such as divorce due to drug or alcohol use, is a cause of homelessness, homelessness is more likely linked to unaffordable housing or low-paying jobs as households who have multiple wage earners, as in married couples, are better able to afford rent. Additionally, drug and alcohol use can isolate an individual from their family, decreasing their levels of affiliation, 
and increasing their risk of homelessness. Previous researchers have also found that divorce or fleeing domestic violence due to substance use by a spouse is a cause of homelessness for women with children. Additionally, a study of homeless women in Ireland found that among women who experienced homelessness for the first time as a child or young adult, it was largely due to family breakdown because of substance use and/or domestic violence by their parent(s) (Mayock et al. 2014).

The lives of chronically homeless individuals have been studied in terms of their "homeless career," or looking at an individual's path of homelessness throughout the life course (Chamberlain and Mackenzie 2006:198). The first pathway is youth homelessness, followed by adult homelessness, which is thought to be caused by family breakdown. Previous research has examined family breakdown due to domestic violence. When an individual begins their homeless career with family breakdown, it has been found to begin with a period in which an individual experiences domestic violence in their home and stays at their home inconsistently due to the violence. This process of coming and going from a home is drawn out for women, who are more likely to be the caretaker for their children and concerned for the housing situation of their children. For some of these individuals, chronic homelessness results after a permanent separation from the home. Intervention is difficult for individuals experiencing family dysfunction due to violence, because violence often remains undetected until the victim is able and willing to get help (Chamberlain and Mackenzie 2006; Snow and Anderson 1993).

\section{PERCEPTIONS OF THE HOMELESS}

Responses to homelessness are influenced by the perceptions of the homeless held by individuals, politicians, and social service providers. During the 1980s, following deinstitutionalization, homelessness was largely believed to be caused by mental illness, so both 
national and local policies focused on creating mental health care options as well as substance abuse facilities (Koegel et al.1996; Jencks 1995). This mentality carried into the 1990s, in that those who were experiencing homelessness were viewed in a similar light as those who had received treatment in a mental health facility (Phelan et al. 1997; Phillips 2015). Further, in a 2015 survey of undergraduate students, substance abuse and mental illness were indicated by students as the largest causes of homelessness (Phillips 2015). While one-third of the homeless do experience mental illness, not all individuals experiencing homelessness struggle with mental illness (Culhane 2010). Mental illness and homelessness are both stigmatized, so when individuals have both traits, they face harsher judgments from society (Phelan et al.1997). Homelessness has been an enduring stigma, meaning that individuals experiencing homelessness have a trait that is deemed undesirable by society (Goffman 1963; Rayburn and Guittar 2013).

Generally, people in the United States attribute homelessness to individual flaws, such as mental illness or substance use, rather than to structural barriers (Cherlin 2015; Robinson 2009). There is variation in this attribution based on the level of education an individual has attained as well as their amount of contact with individuals experiencing homelessness. Knecht and Martinez (2009) developed the contact hypothesis, which explains that increased contact with individuals experiencing homeless or poverty results in members of the middle and upper classes pointing to structural causes of homelessness, rather than individual factors (Lee et al. 2004). Additionally, individuals are more likely to attribute homelessness to structural causes, such as a lack of jobs or affordable housing, if they have knowledge of scholars who study homelessness, often obtained through higher education (Lee et al. 1990; Rayburn and Guittar 2013; Wilson 1996). However, if an individual's contact is through frequently being 
asked for money by a person panhandling, despite their education level, they are more likely to attribute homelessness to individual or fatalistic causes (unfortunate luck) (Phelan et al. 1997; Wilson 1996).

While research has suggested that any type of contact with the homeless reduces stereotypes, the contact hypothesis may also work against the understanding of structural causes of homelessness (Rayburn and Guittar 2013). In recent years, contact has come through social media and pictures of the homeless, which often portray homeless individuals as panhandlers or racial minorities, perpetuating misunderstanding and stereotypes (Lee et al. 2004; Wilson 1996). Additionally, seeing the homeless who live on the streets in large numbers may also reduce a person's sympathy toward the homeless, and those with higher statuses are also thought to attribute homelessness to individual causes, such as laziness, rather than to structural causes if they found economic success through obtaining performance-related promotions in their jobs. Race and biography also have an impact on perceptions of the homeless, despite the amount of contact a person has, as Blacks are more likely to attribute homelessness to structural factors, and those who formerly experienced homelessness are less likely to be willing to support or give money to the homeless (Lee et al. 1990). This could be due to the structural barriers Blacks have faced throughout history regarding accessing housing and jobs, and due to the lack of sympathy demonstrated to the formerly homeless when they were experiencing homelessness (Bunis et al. 1996; Mishel et al. 2012).

Societal views of the homeless have an impact on policy and the availability of homeless services. Many agencies state that their goal is to end homelessness permanently; however, most are focused strictly on meeting immediate needs, such as providing food and shelter and not looking to change structural barriers. Additionally, within service agencies, there is a separation 
between "the server" and "the served," in which the agency employee is apprehensive of the served (the homeless individual), and vice versa (Liebow 1993:120). Due to perpetuating beliefs regarding the link between mental illness and homelessness, funding for programs, especially for women, is focused on providing alcohol and drug support, but there is a lack of programs for those without mental illness or substance abuse concerns (Snow and Anderson 1993). There is also greater sympathy for homeless individuals who are members of families, rather than for sole individuals, which is reflected in program availability (Bunis et al.1996; Snow and Anderson 1993).

\section{RESPONSES TO HOMELESSNESS}

Cities, the federal government, and individual agencies have worked to create long-term and short-term plans and service models for ending homelessness. Long-term solutions include creating Continuums of Care, focusing on rapid rehousing at the federal level, and promoting plans to end homelessness at the state and city levels (Burt 1992; Desmond 2014; Jencks 1995; Lee and Farrell 2003; Lee et al. 2010; Lei 2013; National Alliance to End Homelessness 2016; United States Conference of Mayors 2016; Willse 2010). Short-term solutions include creating additional public spaces and implementing anti-panhandling laws, in addition to increasing emergency shelter beds with the goal of ultimately having increased affordable housing options (Duneier 1999; Jencks 1995; National Alliance to End Homelessness 2016; Venkatesh 2006)

\section{Continuums of Care}

Continuums of Care were created by 1995 revisions to the McKinney-Vento Homeless Assistance Act. The federal government required communities to apply for homeless prevention and housing dollars with only one application, in order to encourage collaborative services. To collaborate, the Department of Housing and Urban Development encouraged the development of 
a community group that includes all homeless and housing service providers to ensure a streamlined service process, called the Continuum of Care (CoC). The four key goals of CoCs are to conduct "outreach, intake, and assessment" of individuals experiencing homelessness to identify housing needs, provide emergency shelters to prevent the number of individuals living on the streets, provide transitional housing services for vulnerable populations, and coordinate rapid rehousing services for individuals and families, including permanent supportive housing (National Alliance to End Homelessness 2010:1). CoCs are also key players in coordinating point-in-time counts. As of 2010, there were $461 \mathrm{CoCs}$ in the United States (2010:1).

The United States Conference of Mayors (2016) indicated successful work by the CoC of Providence, Rhode Island and Salt Lake City, Utah. The CoC of Providence recently implemented a coordinated entry program aligning with their "Zero 2016" goal of ending homelessness, especially family homelessness (2016:35). Social service providers in Providence created an assessment for individuals experiencing homelessness to determine their need for permanent supportive housing, rapid rehousing, or other forms of aid based on a "vulnerability index" (U.S. Conference of Mayors 2016:35). Salt Lake City, Utah also implemented a coordinated entry system to ensure that each individual experiencing homelessness is getting their needs met and has expanded shelter availability based on data from their coordinated entry system (2016).

\section{Federal Plans to End Homelessness}

The establishment of the McKinney-Vento Act in 1987 led to a federal process of dispersing funding to homeless service providers in cities through their Continuum of Care (Willse 2010). Originally, the Act allowed for one billion dollars to be spent on homelessness 
over the course of two years, but it has continued to be extended since its creation (Foscarinis 1996). Originally, the goal of the McKinney-Vento Act was to provide emergency assistance to individuals experiencing homelessness; however, it now provides assistance in funding transitional housing facilities as well as permanent housing options (1996). The act also created an Interagency Council on Homelessness at the Federal level, which organizes federal efforts to end homelessness and provides opportunities for municipalities to collaborate to end homelessness through conferences, training, and technical assistance (United States Interagency Council on Homelessness 2018).

The McKinney-Vento Act required that all municipalities applying for housing funds create a plan to reduce homelessness in their communities, which would be reported to the Department of Housing and Urban Development (1996). HUD, established in 1965 during the War on Poverty, serves as the mediator between municipal, state, and federal policies (Willse 2010). In 1994, President Bill Clinton's administration released a federal plan, entitled The Federal Plan to Break the Cycle of Homelessness, calling for collaborative services and additional affordable housing options (1996). Most recently, HUD released in 2015 an updated plan entitled Opening Doors - Federal Strategic Plan to End Homelessness. This plan highlights three goals, including ending chronic and veteran homelessness by 2020 , preventing and ending family and youth homelessness by 2025, and working toward ending all homelessness (2015).

The Homeless Emergency and Rapid Transition to Housing Act of 2009 included revisions to the McKinney-Vento Act and focused federal funding on rapid rehousing and permanent supportive housing (that is, housing with case management) as a response to homelessness. Financial support for emergency shelters was reduced, moving the burden of 
funding emergency housing to independent charities and municipalities (Lee et al. 2010). This act was revised again in 2012 and changed the definition of homelessness, specifically defining chronic homelessness and differentiating between homeless individuals, homeless families, and individuals with disabilities (HUD 2016). The updates to the act also included a rural housing program and implementation of a Homeless Management Information System (HMIS), which coordinates data collection among service users and ensures confidentiality (2017).

Additionally, HUD distributes an annual report to Congress that describes the results of the point-in-time count, in addition to revisiting federal goals to end homelessness. The most recent report, published in December 2017, emphasizes that the government is attempting to make episodes of homelessness as fleeting as possible before attempting to completely eliminate homelessness. This reflects the same federal goals stated in the Opening Doors Federal Plan to End Homelessness (HUD 2016). Additionally, mayors from 32 cities in 24 states met in 2016 to discuss homelessness and hunger in the United States. The report produced from the United States Conference of Mayors found that 64.5 percent of people experiencing homelessness in the United States are not in families, and the national rate of homelessness is 17 people per 100,000 people (United States Conference of Mayors 2016:5-14). Overall, federal plans to end homelessness have emphasized collaboration and centralization of services with strategic and timely goals, especially in the areas of veteran, chronic, and family and youth homelessness (HUD 2016; HUD 2017).

\section{State and City-Level Solutions}

States and cities receive federal dollars through McKinney-Vento grants to disburse to local agencies to provide aid and shelter to the homeless (Watson 1996). To be eligible for funding, states and cities must have a "Comprehensive Housing Affordability Strategy," which 
outlines the needs both of those living in poverty and the homeless, explains the process of outreach to the homeless, and explains the plan for emergency and transitional shelters in cities (1996:174). States and cities have also created additional plans to end homelessness in their communities. In 2000, the National Alliance to End Homelessness created a comprehensive tenyear plan to end homelessness nationally, and created a campaign to encourage municipalities to do the same. As of 2010, 234 cities had created plans to end homelessness, especially chronic homelessness, by focusing on centralized data collection, poverty prevention, and collaboration (National Alliance to End Homelessness 2010).

Chicago originally created a plan to end homelessness in 2003 and has continually updated its plan (U.S. Conference of Mayors 2016). The city is currently five years into a sevenyear plan to end homelessness. The city continually updates the goals of their plan. Their current goals align with the federal goals for ending homelessness, which include preventing homelessness and promoting speedy housing for those who face homelessness, maintaining affordable housing options, fighting youth homelessness, promoting advocacy and education surrounding homelessness in the city, promoting cooperation and the sharing of resources between agencies, and creating a centralized and coordinated system for those experiencing homelessness (Chicago Plan to End Homelessness 2012). Chicago was the first city to create a plan for ending homelessness, and other cities followed suit in terms of creating similar plans and other programs for ending homelessness (U.S. Conference of Mayors 2016).

The United States Conference of Mayors (2016) and National Alliance to End Homelessness (2016) point to successful city-level initiatives toward ending homelessness. Washington D.C. and Denver, Colorado are considered best practice cities in terms of homeless services (National Alliance to End Homelessness 2016; U.S. Conference of 
Mayors 2016). Washington D.C. has put both federal and local dollars into creating and maintaining permanent supportive housing units. This plan combines housing with emotional, job, and other supportive services for individuals who are formerly homeless. Denver, like Chicago, created a comprehensive plan to end homelessness, entitled Denver's Road Home. Community members from both non-profits and public-sector businesses, in addition to residents and homeless service utilizers, participated in creating the plan, making it highly collaborative. Additionally, utilizing funding from the United Way, local government, and private funds, a commission was created to focus on ending homelessness, as well as to revise on an ongoing basis and implement the city's plan to end homelessness (National Alliance to End Homelessness 2016; U.S. Conference of Mayors 2016).

\section{Public space legislation.}

Cities throughout the United States, especially cities where tourism drives the economy, have created laws against panhandling and street vending in public spaces to keep individuals experiencing homelessness off the streets and out of the public eye (Duneier 1999; Rayburn and Guittar 2013; Snow and Anderson 1993). Since 2006, there has been an 18 percent increase in anti-panhandling legislation (Rayburn and Guittar 2013:159). Previous research on a sample of 187 cities found that twenty-seven percent have criminalized panhandling, and 61 percent have made it illegal in specific areas (Itkowitz 2016; National Law Center on Homelessness and Poverty 2015:27). These laws are considered "broken window laws" because they operate under the assumption that if people see the homeless, home values will decrease and crime will increase (Duneier 1999:226). Duneier (1999) suggests that cities should relax these broken window laws and "normalize deviance" in terms of allowing the homeless or those in poverty to panhandle or sell items on the streets, because doing so assists in giving the homeless 
an income (1999:226; Venkatesh 2006). However, Duneier (1999) also explains that cities need to be very clear in how much they will flex these laws. Snow and Anderson also address the idea of "shadow work," or work apart from the formalized economy, including panhandling and selling stolen items, and explain that while illegal, these types of jobs provide the homeless with an income they normally would not have due to difficulties finding a job due to mental illness, lack of transportation, or a prior criminal record (1993:171; Lee et al. 2010).

Cities throughout the United States also have laws about sleeping in public spaces. In a study of 187 U.S. cities, 57 percent implemented legislation prohibiting camping out in certain public areas, 27 percent of cities implemented laws concerning sleeping in public, and 43 percent made it illegal to sleep in a car (National Law Center on Homelessness and Poverty 2015:8). The National Law Center on Homelessness and Poverty (2015) also found that despite an increase in all types of legislation that criminalize the homeless since 2009 , jail costs are higher than the costs of providing additional housing options. Further, individuals experiencing homelessness should be provided with information about safe housing options; according to the National Law Center on Homelessness and Poverty (2015:11), 74 percent of individuals experiencing homelessness in the Western United States did not know of a safe place to sleep at night (WRAP 2013).

The City of Albuquerque, New Mexico has taken a different approach to panhandling. Mayor Richard Berry implemented a day labor program for individuals panhandling or street vending, called the "There's a Better Way" program. Each day, an Albuquerque non-profit, in partnership with the city government, picks up individuals who are panhandling and offers them day work involving beautification projects throughout the city. Compensation includes a payment of $\$ 9$ per hour, lunch, and an offer to stay in a night 
shelter. This program, which is available four days per week, provides ten individuals per day with employment, with over 100 participants in the past year and a half (Itkowitz 2016). In a 2013 study, Albuquerque also found that with increased efforts and funding to provide housing to the homeless, homeless-related jail expenses decreased by 64 percent in the city (National Law Center on Homelessness and Poverty 2015:9). The National Law Center on Homelessness and Poverty (2015) has called for decreased criminalization of the homeless through alternative outreach and employment programs for the homeless, increased affordable housing options, and encourages the creation of a "Homeless Bill of Rights" (2015:11). The National Coalition for the Homeless has worked toward creating a sample Homeless Bill of Rights and advocates for municipalities to create similar forms of legislation that protect homeless populations from facing discrimination in obtaining permanent housing due to a lack of an address and protection from loitering laws that unequally affect homeless populations (National Coalition for the Homeless 2018).

\section{Emergency Shelters}

Emergency shelters provide a temporary place for individuals experiencing homelessness to stay; however, many cities are lacking shelter bed availability (National Law Center on Homelessness and Poverty 2015). From 2007-2015, the number of emergency shelter beds available in the United States increased by 25 percent. However, the number of transitional housing beds declined by 23.4 percent, and emergency and transitional shelters can only accommodate 76 percent of the homeless on a given night, leaving 24 percent of those living on the streets without shelter options (National Alliance to End Homelessness 2016:57). Even if every shelter bed in the United States were occupied each night, 34,000 individuals 
experiencing homelessness would be without access to a bed (U.S. Conference of Mayors 2016:5).

Because federal dollars have largely been devoted to rapid rehousing, shelters are funded primarily by municipalities and independent non-profits (Willse 2010). Women are more likely to be sheltered than men, with 55 percent of women experiencing homelessness staying in an emergency shelter, in comparison to 71 percent of men remaining unsheltered. Additionally, nine in ten homeless children are staying in an emergency shelter (HUD 2017:8). Therefore, there has been a call for improved shelter conditions, including creating separate shelters for women and women with children (DiBlasio1995; Jencks 1995). Specifically, there is a lack of shelters for "unemployed, single women with no mental health diagnoses" (Perez 2014:12).

\section{Affordable Housing}

Due to federal funding deficits, the United States has experienced a 12.8 percent decrease in affordable housing options since 2001 (National Law Center on Homelessness and Poverty 2015:7). As a result, home evictions have increased in past years and more families are living "doubled up" with other families (2015:13; Desmond 2014). Due to a lack of affordable housing, the government and local cities have encouraged a "housing first model," in which individuals are immediately placed in housing after becoming homeless and then matched with supportive opportunities, such as mental health care or transportation support (2015:37).

Housing choice vouchers also provide permanent housing options. Cities tend to have a waitlist for these vouchers. After an application and approval process, a family or individual that receives a voucher may use their voucher to pay for an apartment (HUD 2017). The tenant is responsible for paying rental costs that are 30 percent of their income, and the voucher will cover the remainder (2017). There has been a call for increased housing choice vouchers from 
homeless support advocates and non-profit professionals, and even more so, a call for increased affordable housing throughout cities (National Law Center on Homelessness and Poverty 2015). CONCLUSION

Homelessness remains an enduring social problem in the United States. Stratification theorists attribute poverty, which is a cause of homelessness, to a lack of jobs, difficulty in accessing the "formal economy," a lack of funding due to governmental regulations, and reduced availability of affordable housing and access to education (Cherlin 2014; Mishel et al. 2012; Royce 2015; Venkatesh 2006). Each of these causes are structural in nature. While some view homelessness as caused by individual factors, such as the homeless having less intellectual ability, being lazy, or experiencing mental illness and substance abuse concerns, increased contact with the homeless as well as increased education may help to reduce these stereotypes (Lee et al. 1990; Rayburn and Guittar 2013; Wilson 1996). Responses to homelessness, including implementing plans to end homelessness and expanding affordable housing options, have focused on reforming structural limitations for those living in poverty and the homeless, while anti-panhandling legislation as well as public assistance restrictions have perpetuated individualistic views on causes of homelessness (Duneier 1999). Due to the reduction in funding by federal and state governments to non-profit agencies, it is essential that communities promote volunteering and education around homelessness to continue to reduce homelessness throughout the United States (National Alliance to End Homelessness 2016). 


\section{REFERENCES}

Acuna, Julia and Bob Erlenbusch. 2009. Homeless Employment Report: Findings and Recommendations. National Coalition for the Homeless. Sacramento, California: Sacramento Steps Forward. Retrieved July 22, 2017 (http://www.nationalhomeless.org/publications/homelessemploymentreport/index.html)

Altheide, David and John Johnson. 1994. "Criteria for Assessing Interpretive Validity in Qualitative Research." Pp. 485-500 in Handbook of Qualitative Research, edited by N.K. Denzin and Y.S. Lincoln. Thousand Oaks, CA: Sage Publications.

American Sociological Association. 1999. Code of Ethics and Policies and Procedures of the ASA Committee on Professional Ethics. The American Sociological Association.

Washington, D.C.: ASA Publications.

Anderson, Nels. 1961. The Hobo: The Sociology of the Homeless Man. Chicago: The University of Chicago Press.

Barman-Adhikari, Anamika, Elizabeth Bowen, Kimberly Bender, Samantha Brown, and Eric Rice. 2016. “A Social Capital Approach to Identifying Correlates of Perceived Social Support Among Homeless Youth.” Child Youth Care Forum 45:691-708.

Bassuk, E. L. and L. Rosenberg. 1988. "Why does Family Homelessness Occur? A Case-Control Study." American Journal of Public Health 78(7):783-788.

Blau, Joel. 1993. The Visible Poor: Homelessness in the United States. Oxford University Press on Demand.

Blau, P.M., \& O.D. Duncan, with A. Tyree. 2000. “The Process of Stratification.” Pp. 325-335 in Social Stratification: Class, Race \& Gender in Sociological Perspective. Edited by D.B. Grusky. Boulder, CO: Westview Press. 
Bourdieu, Pierre. 1985. Distinction: A Social Critique of the Judgment of Taste. Cambridge, MA: Harvard University Press.

Braun, Virginia and Victoria Clarke. 2006. "Using Thematic Analysis in Psychology." Qualitative Research in Psychology 3: 77-101.

Bryman, Alan. 2012. "2001." Social Research Methods, $4^{\text {th }}$ ed. New York, NY: Oxford University Press.

Bunis, William K., Angela Yancik and David A. Snow. 1996. "The Cultural Patterning of Sympathy Toward the Homeless and Other Victims of Misfortune." Social Problems 43(4):387-402.

Burt, Martha M and Barbara E. Cohen 1989. "Differences Among Homeless Single Women, Women with Children, and Single Men.” Social Problems 38(5):508-524.

Burt, Martha M. 1992. Over the Edge: The Growth of Homelessness in the 1980s. New York, NY: Russell Sage Foundation.

Burt, Martha. 2001. "What Will It Take to End Homelessness," The Urban Institute. September, pp.1-6. Retrieved February 4, 2018 (http://webarchive.urban.org/UploadedPDF/end_homelessness.pdf).

Chamberlain, Chris and David Mackenzie. 2006. "Homeless Careers: A Framework for Intervention.” Australian Social Work 59(2):198-212.

Cherlin, Andrew J. 2014. Labor's Love Lost: The Rise and Fall of the Working-Class Family in America. New York, NY: Russell Sage Foundation. 
Chicago Alliance. 2012. Chicago Plan 2.0: A Home for Everyone. Chicago: City of Chicago. Retrieved February 4, 2018 (https://www.cityofchicago.org/content/dam/city/depts/fss/supp_info/Homeless/ChicagoPla n2WEB082712.pdf).

Collins, Rachele C. 2016. "Understanding the Workforce Skills and Development Needs of the Houston Suburban Homeless.” Ph.D. dissertation, Department of Educational Administration and Human Resource Development, Texas A\&M University, College Station, Texas. Retrieved July 22, 2017 (http://oaktrust.library.tamu.edu/bitstream/handle/1969.1/157854/COLLINSDISSERTATION-2016.pdf?sequence=1).

Community Wealth Ventures, the Social Enterprise Alliance, and the Center for the Advancement of Social Entrepreneurship. 2010. Social Enterprise: A Portrait of the Field. Washington, D.C.: Community Wealth Ventures, Inc. Retrieved July 20, 2017 (http://community-wealth.org/sites/clone.community-wealth.org/files/downloads/reportcwv-sea-case.pdf).

Dart, Raymond. 2004. "Being "Business-Like" in a Nonprofit Organization: A Grounded and Inductive Typology." Nonprofit and Voluntary Sector Quarterly 33(2):290-310.

Dear, Michael J. and Jennifer R. Wolch. 1987. "Landscapes of Despair: From Deindustrialization to Homelessness." Journal of Social Policy 18(1):154-156.

Defourny, Jacques and Martha Nyssens. 2006. "Defining Social Enterprise. Social Enterprise: At the Crossroads of Market." Public Policies and Civil Society 7:3-27.

Desmond, Matthew. 2016. Evicted: Poverty and Profit in the American City. New York, NY: Crown. 
Deterding, Mary and Mary Waters. 2017. "Qualitative Coding: A 21 ${ }^{\text {st }}$ Century Approach." Presented at the 2017 American Sociological Society Annual Meeting, August 2017, Montreal, QC.

DeVault, Marjorie L. 1996. "Talking Back to Sociology: Distinctive Contributions of Feminist Methodology." Annual Review of Sociology 22(1):29-50.

Doeringer, Matthew F. 2010. "Fostering Social Enterprise: A Historical and International Analysis." Duke Journal of Comparative \& International Law 20:291-330.

Duneier, Mitchell. 1992. "Slim's Table: Race, Respectability, and Masculinity", Chicago, IL: The University of Chicago Press.

Duneier, Mitchell and Ovie Carter. 1999. Sidewalk. New York City, NY: Macmillan.

The Empowerment Plan. "Our Story." Retrieved July 15, 2017

(http://www.empowermentplan.org/about).

Eyrich, Karin M., David E. Pollio and Carol S. North. 2003. "An Exploration of Affiliation and Replacement Theories of Social Support in Homelessness." Social Work Research 27(4):222-231.

Ferguson, Kristin M. 2007. "Implementing a Social Enterprise Intervention with Homeless, Street-Living Youths in Los Angeles." Social Work 52(2):103-112.

Ferguson, Kristin M., Kimberly Bender, Sanna J. Thompson, Elaine M. Maccio and David Pollio. 2012. "Employment Status and Income Generation among Homeless Young Adults: Results from a Five-City, Mixed-Methods Study." Youth \& Society 44(3):385-407. Ferguson, Kristin M. 2012. "Employment Status and Income Generation among Homeless Young Adults: Results from a Five-City, Mixed-Methods Study." Youth \& Society 44(3):385-407. 
Fontana, Andrea and James Frey. 1994. "Interviewing: The Art of Science." Pp. 361-377 in The Handbook of Qualitative Research., edited by N.K. Denzin and Y.S. Lincoln. Thousand Oaks, CA: Sage Publications.

Foscarinis, Maria. 1996. "The Federal Response: The Stewart B. McKinney Homeless Assistance Act." in Homelessness in America, edited by J. Baumohl. Phoenix, AZ: Oryx Press.

Goffman, Erving. 1963. Stigma: Notes on the Management of a Spoiled Identity. London: Penguin.

Goffman, Erving. 1967. Interaction Ritual: Essays on Face-to-Face Behavior. New York, New York: Pantheon.

Greenberg, Mark and Jim Baumohl. 1996. "Income Maintenance: Little Help Now, Less on the Way." Pp. 63-79 in Homelessness in America, edited by J. Baumohl. Phoenix, AZ: Oryx Press.

Heartside Ministries. 2017. “A Place to Create. The Arts.” Retrieved July 22, 2017 (http://heartside.org/programs/the-arts/).

Hernstein, Richard J. and Charles Murray. 1994. The Bell Curve. New York, NY: The Free Press.

Itkowitz, Colby. 2016. "This Republican Mayor has an Incredibly Simple Idea to Help the Homeless and it Seems to be Working," The Washington Post, August 11. Retrieved February 4, 2018 (https://www.washingtonpost.com/news/inspired-life/wp/2016/08/11/thisrepublican-mayor-has-an-incredibly-simple-idea-to-help-the-homeless-and-it-seems-to-beworking/?utm_term=.934ecdd $4835 \mathrm{c}$ ). 
Jencks, Christopher. 1995. The Homeless. Cambridge, MA: Harvard University Press.

Koegel, Paul, Audrey Burnam and Jim Baumohl. 1996. "The Causes of Homelessness." Pp. 24 in Homelessness in America, edited by Jim Baumohl. Phoenix, AZ: Oryx Press.

LaGory, Mark, Ferris J. Ritchey and Jeff Mullis. 1990. "Depression among the Homeless." Journal of Health and Social Behavior 87-102.

LaGory, Mark, Ferris J. Ritchey and Kevin Fitzpatrick. 1991. "Homelessness and Affiliation." The Sociological Quarterly 32(2):201-218.

Lam, Julie A. and Robert A. Rosenheck. 2000. "Correlates of Improvement in Quality of Life among Homeless Persons with Serious Mental Illness." Psychiatric Services 51(1):116-118.

Lankenau, Stephen E. 1999. "Stronger Than Dirt Public Humiliation and Status Enhancement Among Panhandlers." Journal of Contemporary Ethnography 28(3):288-318.

Leadbeater, Simon. 2013. "Third Sector Perspectives Versus Business Sense: One Charity's Quest for Social Enterprise to Help London's Homeless." Voluntary Sector Review 4(2):265274.

Lee, Barrett A., Sue H. Jones and David W. Lewis. 1990. "Public Beliefs about the Causes of Homelessness." Social Forces 69: 253-265.

Lee, Barrett A. and Chad R. Farrell. 2003. "Buddy, Can You Spare a Dime? Homelessness, Panhandling, and the Public." Urban Affairs Review 38(3):299-324.

Lee, Barrett A., Kimberly A. Tyler and James D. Wright. 2010. "The New Homelessness Revisited." The Annual Review of Sociology 36:501-521.

Lei, Lei. 2013. "Employment, Day Labor, and Shadow Work among Homeless Assistance Clients in the United States." Journal of Poverty 17(3):253-272. 
Liebow, Elliot. 1993. Tell them Who I Am. New York City, NY: Simon and Schuster.

Lippert, Adam M. and Lee A. Barrett. 2015. "Stress, Coping, and Mental Health Differences among Homeless People." Sociological Inquiry 85(3):343-374.

Luker, Kristin. 2012. Salsa Dancing into the Social Sciences. Cambridge, MA: Harvard University Press.

Lyon, Fergus and Mark Ramsden. 2006. "Developing Fledgling Social Enterprises? A Study of the Support Required and Means of Delivering it." Social Enterprise Journal 2(1):27-41.

Marx, Karl. 1867/2001. Alienation and Social Classes. Classes in Capitalism and Pre-capitalism. Ideology and Class. Value and Surplus value. Pp. 87-105 in Social Stratification: Class, Race, \& Gender in Sociological Perspective, edited by D.B. Grusky. Boulder, CO: Westview Press.

Mayock, Paula, Sarah Sheridan, and Sarah Parker. 2014. "It's just like we're going around in circles and going back to the same thing ...': The Dynamics of Women's Unresolved Homelessness." Housing Studies 30(6): 877-900.

Mishel, Lawrence, Josh Bivens, Elise Gould, and Heidi Shierholz. 2012. The State of Working America. Ithaca, New York: Cornell University Press.

National Alliance to End Homelessness. 2010. "Ten Year Plan." Retrieved May 5, 2017 (http://www.endhomelessness.org/pages/ten-year-plan).

National Alliance to End Homelessness. 2012. "Changes in the HUD Definition of Homeless." Retrieved November 28, 2016 (http://www.endhomelessness.org/library/entry/changes-in-the-hud-definition-of-homeless). National Alliance to End Homelessness. 2012. "What is a Point in Time Count?" Retrieved February 21, 2018 (https://endhomelessness.org/resource/what-is-a-point-in-time-count/). 
National Alliance to End Homelessness. 2016. The State of Homelessness in America.

Washington, D.C.: The National Alliance to End Homelessness. Retrieved November 28, 2016(http://www.endhomelessness.org/page//files/2016\%20State\%20Of\%20Homelessness. pdf).

National Coalition for the Homeless. 2007. Employment and Homelessness. Washington, D.C: National Coalition for the Homeless. Retrieved November 28, 2016 (http://www.nationalhomeless.org/publications/facts/employment.html).

National Coalition for the Homeless. 2009. "Homelessness in America." Washington, D.C.: National Coalition for the Homeless. Retrieved May 5, 2017. (http://nationalhomeless.org/about-homelessness/).

National Coalition for the Homeless. 2018. Homeless Bill of Rights. Retrieved February 23, 2018 (http://nationalhomeless.org/campaigns/bill-of-right/).

National Coalition for the Homeless. N.d. Homelessness in America. Retrieved December 1, 2016 (http://nationalhomeless.org/about-homelessness/).

National Law Center on Homelessness and Poverty. 2015. Housing Not Handcuffs: Ending the Criminalization of Homelessness in U.S. Cities. Washington D.C.: The National Law Center on Homelessness and Poverty. Retrieved February 4, 2018 (https://www.nlchp.org/documents/Housing-Not-Handcuffs).

Phillips, Lindsay. 2015. "Homelessness: Perception of Causes and Solutions." Journal of Poverty 19(1):1-19.

Putnam, Robert. 1993. "The Prosperous Community: Social Capital and Public Life." The American Prospect 4(13):1-11.

Putnam, Robert. 2000. Bowling Alone. New York, NY: Simon and Schuster. 
Rayburn, Rachel L. and Nicholas A. Guittar. 2013. "This is Where You are Supposed to Be. How Homeless Individuals Cope with Stigma." Sociological Spectrum 33(2):159-174. Rosenberg, Mike. 2017. "Why Are Home Prices So High? Seattle Gas 2nd-Lowest Rate of Homes for Sale in U.S.” The Seattle Time, January 18. Retrieved January 18, 2018 (https://www.seattletimes.com/business/real-estate/why-are-home-prices-so-high-seattlehas-2nd-lowest-rate-of-homes-for-sale-in-us/).

Rossi, Peter H. 1991. Down and Out in America: The Origins of Homelessness. Chicago, IL: University of Chicago Press.

Royce, Edward. 2015. Poverty and Power: The Problem of Structural Inequality. Lanham, MD: Rowman \& Littlefield.

Semega, Jessica L., Kayla R. Fontenot, Melissa A. Kollar. 2017. Income and Poverty in the United States: 2016. Washington D.C.: United States Department of Commerce. Retrieved February 22, 2018 (https://www.census.gov/content/dam/Census/library/publications/2017/demo/P60-259.pdf).

Sewell, W.H., A.O. Holler, \& A. Portes. 2001. The Educational and Early Occupational Attainment Process. Pp. 410-421 in Social stratification: Class, Race \& Gender in Sociological Perspective, edited by D.B. Grusky. Boulder, CO: Westview Press.

Shlay, Anne B. and Peter H. Rossi. 1992. "Social Science Research and Contemporary Studies of Homelessness." Annual Review of Sociology 18(1):129-160.

Shinn, Mary. 2017. “Latest Homeless Count Likely Underestimates Numbers in Durango and Colorado.” The Durango Herald, December 7. Retrieved January 18, 2018 (https://durangoherald.com/articles/198628-latest-homeless-count-likely-underestimatesnumbers-in-durango-and-colorado). 
Snow, David A. and Leon Anderson. 1993. Down on their Luck: A Study of Homeless Street People. Oakland, CA: University of California Press.

Socentcity. 2017. From the Ground Up: Defining Social Enterprise Ecosystems in the U.S. Washington, D.C.: Sage Communications. Retrieved July 10, 2017 (http://www.socentcity.org/downloads/Quantifying\%20Social\%20Enterprise\%20Ecosystem s\%20in\%20the\%20U.S.pdf).

Stack, Carol B. 1974. All Our Kin: Strategies for Survival in a Black Community. New York, NY: Harper Torchbooks.

Stanfield, John I. 1994. "Ethnic Modeling in Qualitative Research." Pp. 175-189 in The Handbook of Qualitative Research., edited by N.K. Denzin and Y.S. Lincoln. Thousand Oaks, CA: Sage Publications.

Stovall, Jeffery and Joseph Flaherty. 1994. "Homeless Women, Disaffiliation, and Social Agencies.” International Journal of Social Psychiatry 40(2):135-140.

Strauss, Anselm and Juliet Corbin. 1994. "Grounded Theory Methodology: An Overview." Pp. 273-286 in The Handbook of Qualitative Research., edited by N.K. Denzin and Y.S. Lincoln. Thousand Oaks, CA: Sage Publications.

Swidler, Ann. 1986. "Culture in Action: Symbols and Strategies.” American Sociological Review 51(2):273-286.

Teasdale, Simon. 2009. "Innovation in the Homelessness Field: How does Social Enterprise Respond to the Needs of Homeless People?" Birmingham, United Kingdom: Third Sectre Research Center.

Teasdale, Simon. 2010. "Models of Social Enterprise in the Homelessness Field." Social Enterprise Journal 6(1):23-34. 
Teasdale, Simon. 2012. "Negotiating Tensions: How do Social Enterprises in the Homelessness Field Balance Social and Commercial Considerations?" Housing Studies 27(4):514-532.

The United States Conference of Mayors. 2016. Hunger and Homelessness Survey. United States Interagency Council on Homelessness. "About USICH." Retrieved July 10, 2017. (https://www.usich.gov/about-usich).

The U.S. Department of Housing and Urban Development. 2015. Opening Doors: Federal Strategic Plan to Prevent and End Homelessness. Washington D.C.: The U.S. Department of Housing and Urban Development. Retrieved February 4, 2018 (https://www.usich.gov/resources/uploads/asset_library/USICH_OpeningDoors_Amendmen t2015_FINAL.pdf).

The U.S. Department of Housing and Urban Development. 2016. The 2016 Annual Homeless Assessment Report to Congress. Washington, DC.: The U.S. Department of Housing and Urban Development. Retrieved December 12, 2017 (https://www.hudexchange.info/resources/documents/2016-AHAR-Part-1.pdf).

The United States Department of Housing and Urban Development. 2017. "Homeless Emergency Assistance and Rapid Transition to Housing Act." Retrieved May 5, 2017. (https://www.hudexchange.info/homelessness-assistance/hearth-act/).

The U.S. Department of Housing and Urban Development. 2017. The 2017 Annual Homeless Assessment Report to Congress. Washington, D.C.: The U.S. Department of Housing and Urban Development. Retrieved January 19, 2018

Thornley, Ben. 2013. "The Facts on U.S. Social Enterprise." The Huffington Post, January 8. Retrieved July 10, 2017 (http://www.huffingtonpost.com/ben-thornley/socialenterprise_b_2090144.html). 
Toro, Paul A., Carolyn J. Tompsett, Sylvie Lombardo, Pierre Philippot, Hilde Nachtergael, Benoit Galand, Natascha Schlienz, Nadine Stammel, Yanélia Yabar and Marc Blume. 2007. "Homelessness in Europe and the United States: A Comparison of Prevalence and Public Opinion." Journal of Social Issues 63(3):505-524.

Tucker, Robert. 1978. The Marx Engels Reader. New York City, NY: W.W. Norton \& Company.

Venkatesh, Sudhir A. 2006. Off the Books. Cambridge, MA: Harvard University Press.

Walsh, Christine A., Kate Beamer, Carla Alexander, Micheal L. Shier, Mandy Loates and John R. Graham. 2010. "Listening to the Silenced: Informing Homeless Shelter Design for Women through Investigation of Site. Situation, and Service." Social Development Issues 32(3):35-49.

Watson, Vicki. 1996. "Responses by the States to Homelessness." Pp. 172 in Homelessness in America, edited by Jim Baumohl. Phoenix, AZ: Oryx Press.

Weber, Max. (1914/1946/1982). “Class and Status.” Pp. 301-307 in Max Weber: Essays in Sociology, edited by Gerth, H.H. and C.W. Mills, and reprinted in L.A. Coser \& B. Rosenberg, Sociological Theory, Fifth Edition: A Book of Reading. New York City, NY: MacMillan.

Weber, Max. 1946. From Max Weber: Essays in Sociology. New York, NY: Oxford University Press.

Weber, Christopher and Geoff Mulvihill. 2017. "US homeless count rises, pushed by crisis on the West Coast." The Durango Herald, December 6. Retrieved January 21, 2018 (https://durangoherald.com/articles/198404-us-homeless-count-rises-pushed-by-crisis-onthe-west-coast). 
Whiting, Basil J. 1994. Employing the Formerly Homeless: Adding Employment to the Mix of Housing and Services. Collingdale, PA: DIANE Publishing.

Willse, Craig. 2010. "Neo-Liberal Biopolitics and the Invention of Chronic Homelessness." Economy and Society 39(2):155-184.

The Women's Bean Project. "Our Program." Retrieved July 10, 2017 (https://www.womensbeanproject.com/our-impact/our-program/).

Yin, Robert K. 1994. Case Study Research: Design and Methods. Thousand Oaks, CA: Sage Publications. 


\section{APPENDIX A. RECRUITMENT ADVANCE EMAIL FOR EXECUTIVE DIRECTOR}

[Date]

Dear [insert name]:

Within the next week, I will be calling you regarding a project about the impacts a social enterprise employing homeless individuals has on employees, employers, and communities. Your enterprise was selected as a potential case study for this project because of your social goal of employing the homeless coupled with your economic goal of being a sustainable business in the public market. Your insights will provide perspective regarding how your social enterprise was established, the struggles and successes that your social enterprise faces, and the relationship between your social enterprise and your community.

I am writing in advance of my telephone call because I have found that many people appreciate being advised that a research study is in progress, and that they will be contacted. There are two components to this research: a case study and interviews. I would like to conduct interviews, focusing on your successes and struggles while also learning more about the employees of your social enterprise and the social enterprise's role in the community. I would also interview a sample of managers/ supervisors and employees to learn about the impacts of working in a social enterprise on employees. All employee interviews will occur outside of their work hours, and their participation is completely optional.

Measures will be taken to protect the identity of your business, you, and your employees. The name of your social enterprise will never be disclosed, and participants' names will also never be disclosed. You may withdraw from the study or choose not to answer a question at any time without penalty. This project will culminate in a report that describes your social enterprise, your role as an owner, and the perspective of a sample of your employees. You may request a copy of the final report.

I will be calling you within the next few days to confirm that you received this email and to see if you are willing to participate in this study. If you are willing to participate, we can set up a time for an interview. Interviews will last between 45 and 90 minutes and can occur at your enterprise or at a location that is convenient for you.

I would be most happy to answer any questions you might have. Please feel free to contact me at mcook12@ilstu.edu or 517-410-5455. You may also contact the ISU faculty research advisor for this project, Marion Willetts, at mcwille@ilstu.edu or 309-438-8668. Further, if you have any questions about your rights as a subject/participant in this research, or if you feel you have been placed at risk, you can contact the Research Ethics \& Compliance Office at Illinois State University at (309) 438-2529 or via email at rec@ilstu.edu.

Sincerely,

Molly Cook, Researcher

Sociology Master's Student

Illinois State University
Marion Willetts, Ph.D., Faculty Advisor

Associate Professor of Sociology

Illinois State University 


\section{APPENDIX B. PARTICIPATION FOLLOW-UP CALL SCRIPT}

Hello, my name is Molly Cook, and I am a graduate student researcher in the Sociology Department at Illinois State University. The reason I am contacting you is because a study is being conducted on a social enterprise that employs the homeless. Your social enterprise was selected as a potential case study site for this study because of your social goal of employing individuals experiencing homelessness, coupled with your economic goal as a business. I wish to interview you, managers, and employees at your enterprise. Measures will be taken to protect the identities of you, your enterprise, and your employees. The name of your social enterprise will never be disclosed, and the names of participants will never be disclosed. You may withdraw from the study or choose to not answer a question without penalty. I sent an email to you a few days ago with further details and am hoping to talk with you about the possibility of your social enterprise participating in this case study. If you are willing to participate, when would be a convenient time for you to set up an interview? 


\section{APPENDIX C. EMPLOYEE RECRUITMENT PHONE CALL}

Hello, my name is Molly Cook, and I am a graduate student researcher in the Sociology Department at Illinois State University. The reason I am contacting you is because a study is being conducted on a social enterprise that employs the homeless. You are one of a sample of employees and manager/supervisors being contacted from your workplace to participate in an interview. Interviews will last 45-90 minutes outside of your work hours at a location convenient to you, and your participation is completely voluntary. You may also choose to withdraw from the study at any time without penalty. Your responses to interview questions will never be connected to your name, and your name as well as the name of your workplace will never be identified in any reports. Interview questions will focus on your work history as well as your experience working at We require that participants work over 20 hours per week at the enterprise and that you have worked at the enterprise for at least eight weeks. I gave you a letter a few days ago with further details and am hoping to talk with you about the possibility of your participating in this study. If you are willing to participate, when would be a convenient time for you to set up an interview? 


\title{
APPENDIX D. EMPLOYEE AND MANAGER/SUPERVISOR RECRUITMENT LETTER
}

\author{
[Date]
}

\section{Dear [insert name]:}

I am contacting you regarding a project about the impacts a social enterprise employing homeless individuals has on employees, employers, and communities. Social enterprises have both social and economic goals and have been suggested as a way to provide individuals experiencing homelessness with a job and connection to other services, such as housing and transportation services. Your insights, as an employee and/or manager/supervisor at a social enterprise, will provide perspective regarding the struggles and successes of working at a social enterprise.

I am writing to follow up on our telephone call because I have found that many people appreciate being advised that a research study is in progress, and that they will be contacted. You are being contacted as a part of a sample of managers/supervisors and employees at your organization to participate in an interview. Participation is completely voluntary. Interviews will be conducted individually and will last 45-90 minutes. Interviews will be transcribed and audio recorded. Questions will focus on your work history and your experience working at this social enterprise. Interviews will take place outside of your work hours at a location convenient to you. To participate in the interview, you should work an average of 20 hours per week at this social enterprise and have been employed at the enterprise for at least eight weeks prior to participation. If you are willing to participate, please respond to this letter in person or via phone or email so that we can schedule a time for an interview.

Measures will be taken to protect your identity. Your responses will never be connected to your name and will never be shared with your supervisor or the owner of your workplace. Additionally, the name of your workplace will never be revealed in any reports. You may withdraw from the study or choose to not answer a question at any time without penalty. This project will culminate in a report that describes your workplace and your role and experience as an employee, as well as the perspective of the owner of this social enterprise. You may request a copy of the final report.

I would be most happy to answer any questions you might have. Please feel free to contact me, at mcook12@ilstu.edu or 517-410-5455. You may also contact the ISU faculty research advisor for this project, Marion Willetts, at mcwille@ilstu.edu or 309-438-8668. Further, if you have any questions about your rights as a subject/participant in this research, or if you feel you have been placed at risk, you can contact the Research Ethics \& Compliance Office at Illinois State University at (309) 438-2529 or via email at rec@ilstu.edu.

Sincerely,

Molly Cook, Researcher

Sociology Master's Student

Illinois State University
Marion Willetts, Ph.D., Faculty Advisor

Associate Professor of Sociology

Illinois State University 


\section{APPENDIX E. CASE STUDY COMMITMENT EMAIL}

[Date]

Dear [insert name]:

Thank you for agreeing to participate in a case study on social enterprises that employ individuals experiencing homelessness. Molly Cook, the co-principal investigator in this study, will interview you and other owners, as well as interview three to six employees and managers/supervisors of your enterprise. In agreeing to participate, you are agreeing to answer follow-up questions from the researcher and consenting to being audio recorded. Audio recordings will be deleted by December 2018, and transcriptions and audio recordings will be kept on Molly Cook's personal laptop and will be password protected and encrypted. Additionally, your name, your employees' names, and the name of your enterprise will never be revealed in this study. There is a risk for a breach in confidentiality if others are able to determine your or your employees' identities, but the researcher will safeguard your identity by giving you and other participants pseudonyms. Participation in this study is completely voluntary, and you may choose to withdraw from the study at any time without penalty.

Please respond to this email indicating your agreement to participate and to schedule a time for an interview. If you have any questions, please feel free to reach out to Molly Cook at (517) 410-5455 or at mcook12@ilstu.edu. You can also reach out to the ISU faculty advisor for this project, Dr. Marion Willetts, at mcwille@ilstu.edu or at 309-438-8668. Further, if you have any questions about your rights as a subject/participant in this research, or if you feel you have been placed at risk, you can contact the Research Ethics \& Compliance Office at Illinois State University at (309) 438-2529 or via email at rec@ilstu.edu.

Sincerely,

Molly Cook, Researcher

Sociology Master's Student

Illinois State University
Marion Willetts, Ph.D., Faculty Advisor

Associate Professor of Sociology

Illinois State University 


\section{APPENDIX F. INFORMED CONSENT FOR OWNER}

\section{Informed Consent For Owner: A Social Enterprise's Response to Homelessness}

\section{Introduction}

This research study is being conducted by Dr. Marion Willetts, an associate professor of Sociology at Illinois State University and by Molly Cook, a Master's student in Sociology and Applied Community and Economic Development Fellow at Illinois State University to determine the struggles and successes social enterprises that employ the homeless face, and the impact that social enterprises that employ individuals experiencing homeless have on enterprise owners, employees, and the community. You must be over 18 years of age to participate in this study.

\section{Procedures}

If you choose to take part in this research study, you will be asked to participate in a semistructured interview with approximately 25 questions. This interview will last between 45 and 90 minutes and will be audio recorded. The location and time of the interview will be at your convenience.

\section{Risks/Discomforts}

The risks associated with this research are no greater than those encountered in your daily conversations discussing your workplace and the work that you do. Additionally, while all participants will be given pseudonyms, characteristics such as age, gender, and race will be described, so there is a risk that participants would be identified.

The researcher is taking steps to safeguard you against these risks by giving you a pseudonym in any research publications and having the faculty research advisor on this project read any final publications to ensure that there are no breaches in confidentiality. Any notes and transcriptions will also be stored on a password protected and encrypted file on the researcher's personal computer to reduce risks. The names of participants, as well as the name of the social enterprise, will never be identified.

\section{Benefits}

There are no direct benefits to participants. However, your participation will help us gain useful knowledge about social enterprises that employ individuals experiencing homelessness. Your responses will be compiled with other responses to determine themes that will serve as a resource for social enterprises that employ individuals experiencing homelessness; however, your name will not be disclosed in order to protect your identity.

\section{Confidentiality}

All information provided will remain confidential. Participants' names will never be disclosed, however, information regarding gender and age of participants may be disclosed in final publications. Audio recordings will be deleted by December 2018, and all transcriptions will be password protected on the researcher's computer.

\section{Participation}

Participating in this study is voluntary. You may discontinue participation at any time without penalty. You can also skip questions you do not wish to answer. 


\section{Conflicts of Interest}

There are no conflicts of interest in this study. There is no outside funding source.

\section{Questions about the Research}

For questions about this research Molly Cook can be contacted at 517-410-5455 or mcook12@ilstu.edu. Dr. Marion Willetts, the ISU faculty advisor for this research, can also be contacted at 309-438-8668 or mcwille@ilstu.edu.

You will be given a copy of this consent form for your records.

I consent to participating in the above study.

Signature

Date

I consent to being audio recorded.

Signature

Date

If you have any questions about your rights as a subject/participant in this research, or if you feel you have been placed at risk, you can contact the Research Ethics \& Compliance Office at Illinois State University at (309) 438-2529 or via email at rec@ilstu.edu 


\section{APPENDIX G. INFORMED CONSENT FOR MANAGERS/SUPERVISORS}

\section{Introduction}

This research study is being conducted by Dr. Marion Willetts, an associate professor of Sociology at Illinois State University and by Molly Cook, a Master's student in Sociology and Applied Community and Economic Development Fellow at Illinois State University to determine the struggles and successes social enterprises that employ the homeless face, and the impact that social enterprises that employ individuals experiencing homeless have on enterprise owners, employees, and the community. You must be over 18 years of age to participate in this study.

\section{Procedures}

If you choose to take part in this research study, you will be asked to participate in a semistructured interview with approximately 25 questions. This interview will last between 45 and 90 minutes and will be audio recorded. The location and time of the interview will be at your convenience.

\section{Risks/Discomforts}

The risks associated with this research are no greater than those encountered in your daily conversations discussing your workplace and the work that you do. Additionally, while all participants will be given pseudonyms, characteristics such as age, gender, and race will be described, so there is a risk that participants would be identified. There is also a risk that responses could pose a risk for employment if an employer is able to figure out the identity of participants. However, employers will not be given a list of participants and individual responses will not be linked with individual participants.

The researcher is taking steps to safeguard you against these risks by giving you a pseudonym in any research publications and having the faculty research advisor on this project read any final publications to ensure that there are no breaches in confidentiality. Any notes and transcriptions will also be stored on a password protected and encrypted file on the researcher's personal computer to reduce risks. The names of participants, as well as the name of the social enterprise, will never be identified.

\section{Benefits}

There are no direct benefits to participants. However, your participation will help us gain useful knowledge about social enterprises that employ individuals experiencing homelessness. Your responses will be compiled with other responses to determine themes that will serve as a resource for social enterprises that employ individuals experiencing homelessness; however, your name will not be disclosed in order to protect your identity.

\section{Confidentiality}

All information provided will remain confidential. Participants' names will never be disclosed, however, information regarding gender and age of participants may be disclosed in final publications. Audio recordings will be deleted by December 2018, and all transcriptions will be password protected on the researcher's computer. 


\section{Participation}

Participating in this study is voluntary. This research is not employer sponsored, and your continued employment is in no way associated with your participation in this study. You may discontinue participation in this study at any time without penalty. You can also skip questions you do not wish to answer.

\section{Conflicts of Interest}

There are no conflicts of interest in this study. There is no outside funding source.

\section{Questions about the Research}

For questions about this research Molly Cook can be contacted at 517-410-5455 or mcook12@ilstu.edu. Dr. Marion Willetts, the ISU faculty advisor for this research, can also be contacted at 309-438-8668 or mcwille@ilstu.edu.

You will be given a copy of this consent form for your records.

I consent to participating in the above study.

Signature

Date

I consent to being audio recorded.

Signature

Date

If you have any questions about your rights as a subject/participant in this research, or if you feel you have been placed at risk, you can contact the Research Ethics \& Compliance Office at Illinois State University at (309) 438-2529 or via email at rec@ilstu.edu 


\section{APPENDIX H. INFORMED CONSENT FOR EMPLOYEES}

\section{Introduction}

This research study is being conducted by Dr. Marion Willetts, an associate professor of Sociology at Illinois State University and by Molly Cook, a Master's student in Sociology and Applied Community and Economic Development Fellow at Illinois State University to determine the struggles and successes social enterprises that employ the homeless face, and the impact that social enterprises that employ individuals experiencing homeless have on enterprise owners, employees, and the community. You must be over 18 years of age to participate in this study.

\section{Procedures}

If you choose to take part in this research study, you will be asked to participate in a semistructured interview with approximately 25 questions. This interview will last between 45 and 90 minutes and will be audio recorded. The location and time of the interview will be at your convenience.

\section{Risks/Discomforts}

The risks associated with this research are no greater than those encountered in your daily conversations discussing your workplace and the work that you do. Additionally, while all participants will be given pseudonyms, characteristics such as age, gender, and race will be described, so there is a risk that participants would be identified. There is also a risk that responses could pose a risk for employment if an employer is able to figure out the identity of participants. However, employers will not be given a list of participants and individual responses will not be linked with individual participants.

The researcher is taking steps to safeguard you against these risks by giving you a pseudonym in any research publications and having the faculty research advisor on this project read any final publications to ensure that there are no breaches in confidentiality. Any notes and transcriptions will also be stored on a password protected and encrypted file on the researcher's personal computer to reduce risks. The names of participants, as well as the name of the social enterprise, will never be identified.

\section{Benefits}

There are no direct benefits to participants. However, your participation will help us gain useful knowledge about social enterprises that employ individuals experiencing homelessness. Your responses will be compiled with other responses to determine themes that will serve as a resource for social enterprises that employ individuals experiencing homelessness; however, your name will not be disclosed in order to protect your identity.

\section{Confidentiality}

All information provided will remain confidential. Participants' names will never be disclosed, however, information regarding gender and age of participants may be disclosed in final publications. Audio recordings will be deleted by December 2018, and all transcriptions will be password protected on the researcher's computer. 


\section{Participation}

Participating in this study is voluntary. This research is not employer sponsored, and your continued employment is in no way associated with your participation in this study. You may discontinue participation in this study at any time without penalty. You can also skip questions you do not wish to answer.

\section{Conflicts of Interest}

There are no conflicts of interest in this study. There is no outside funding source.

\section{Questions about the Research}

For questions about this research Molly Cook can be contacted at 517-410-5455 or mcook12@ilstu.edu. Dr. Marion Willetts, the ISU faculty advisor for this research, can also be contacted at 309-438-8668 or mcwille@ilstu.edu.

You will be given a copy of this consent form for your records.

I consent to participating in the above study.

Signature

Date

I consent to being audio recorded.

Signature

Date

If you have any questions about your rights as a subject/participant in this research, or if you feel you have been placed at risk, you can contact the Research Ethics \& Compliance Office at Illinois State University at (309) 438-2529 or via email at rec@ilstu.edu 


\section{APPENDIX I. INTERVIEW QUESTIONS FOR ENTERPRISE OWNER}

Biography:

1.) Please tell me a little bit about yourself and your role within this organization.

2.) What is your work and educational history?

- How long have you owned this enterprise?

- Why do you own this enterprise?

- How did you come to own this enterprise?

\section{Enterprise History:}

3.) Why is the social enterprise currently operating at this location?

- Has your enterprise always been at this location?

- If no, where was it located previously?

- Why did you relocate?

4.) How many years has this enterprise been in existence?

- Will you explain to me the timeline for the creation of this enterprise?

5.) Please tell me a little bit about the mission and purpose of the organization.

6.) What would you say is the primary goal of your enterprise?

- What would you say are the economic goals of your enterprise?

- What would you say are the social goals of your enterprise? (connecting the homeless with jobs or services)

- Would you say that the primary goal of this enterprise is social (connecting the homeless with jobs or services), economic (making a profit), or a combination (such as selffulfillment)?

7.) How would you describe the culture of your enterprise? By culture, I mean the commonly understood beliefs, common rituals and ways of speaking, and ongoing ceremonies, meetings, or activities in an enterprise.

8.) Do you receive funding from any outside sources, such as individual donors, foundations, grants, or the government?

- Have your funding sources changed over the course of the enterprise's existence? If yes, will you please explain this to me? 


\section{Employees:}

9.) How many employees currently work here?

10.) How would you describe the employees in terms of gender, race/ethnicity and age?

11.) How many of the employees here are currently homeless? By homeless I mean lacking a place to sleep at night, including residing in an emergency shelter, on the streets, in a transitional housing unit, or a place not meant for human habitation.

12.) How many of your employees are formerly homeless?

13.) On average at any given time, what percentage of your employees are homeless?

- What percentage are formerly homeless?

- Are any managers/supervisors homeless or formerly homeless?

14.) What are your employees' estimated education levels (e.g., less than high school, high school graduate, vocational training, certifications, some college, college graduate, and some graduate school)?

15.) Do you offer job training opportunities for employees?

- If yes, what sorts of opportunities do you offer?

- How often do you offer these opportunities?

- Who coordinates job training opportunities?

- How many employees typically participate?

- Do you see a change in employee work performance after participating in job training opportunities?

If yes, will you describe this change to me?

16.) Do you provide support for employees in finding housing or provide connections to other social services?

- If yes, what kinds of support do you offer?

- How often do you offer these supports?

- Who coordinates these supports?

- How many employees utilize support opportunities?

- Do you see a change in work performance after an employee participates in these opportunities?

- If yes, will you describe this change to me?

17.) On average, how long do non-managerial/non-supervisory employees usually stay at this enterprise? 
- Where do they tend to go after leaving their job here?

18.) On average, how long do managerial/supervisory employees usually stay at this enterprise?

- Where do they tend to go after leaving their job here?

19.) Have you had successes at this enterprise in terms of your employees? If so, will you describe these successes?

- How many employees that are experiencing homelessness at the time of being first hired have you had since being the owner of this enterprise?

- How many employees have gone on to find permanent housing who did not have housing prior to employment?

- Do you notice emotional changes in your employees, such as a sense of self-fulfillment, increased self-confidence, etc?

- How many employees have secured other jobs after working at this enterprise?

$\circ$ What kinds of jobs do employees tend to hold after working here?

20.) Have you had struggles at this enterprise in terms of employees? Examples of struggles may include hiring, retaining, training, or motivating employees. If yes, will you please explain these to me?

- What is your process for hiring employees?

$\checkmark$ Has this process changed over the years? If so, will you describe this change to me?

- How do you motivate employees?

- Have you had any difficulties motivating employees? If so, will you describe this difficulty?

21.) What barriers do you see to individuals experiencing homelessness gaining full-time employment in living wage jobs? By living wage I mean a wage that allows a person to afford housing, food, clothes, and sustain basic needs.

22.) What is your view regarding the labor market and what role employers can/should play in advancing or limiting job opportunities for homeless individuals?

- Should employers offer job training for individuals experiencing homelessness?

$\circ$ Why or why not?

- Should employers provide transportation for employees experiencing homelessness to work?

$\circ$ Why or why not?

- Should employers offer childcare for homeless employees with children?

○ Why or why not?

- Should homeless employees hold managerial or supervisory positions at an enterprise?

$\circ$ Why or why not? 


\section{Community}

23.) Do you partner with other businesses or agencies in the community?

- If yes, will you explain in what way(s) you collaborate?

24.) Is this business sustainable in the community? By that, I mean do you see your business remaining within the community for at least the next five years?

- If yes, why it sustainable? If no, why is it not sustainable?

25.) Do you have any plans to reduce or expand your enterprise? If so, will you explain these plans to me? 


\section{APPENDIX J. INTERVIEW QUESTIONS FOR SOCIAL ENTERPRISE EMPLOYEES}

\section{Biography}

1.) Please tell me a little bit about yourself, your background, and your housing situation.

2.) Are you currently homeless? By homeless I mean lacking a place to sleep at night, including residing in an emergency shelter, on the streets, in a transitional housing unit, or a place not meant for human habitation.

- If so, for how long have you been homeless?

- If no, when was your last period of homelessness?

3.) How long have you been homeless in total over your lifetime?

Work History

4.) What are the workforce skills that you currently have? Workforce skills are the skills that have prepared you for this job that come as a result of training, education, or previous experience.

- How did you develop these workforce skills?

- Where did you develop these workforce skills?

5.) How much education have you had (e.g., less than high school, high school graduate, vocational training, certifications, some college, college graduate, some graduate school)?

6.) How did you get this job?

7.) How long have you worked at this enterprise?

Experience Working at the Enterprise

8.) Do you need any workforce skills assistance and/or training to keep this job?

- If yes, will you please describe to me the workforce skills assistance and/or training that you need?

9.) Do you need support in terms of transportation, childcare, or housing assistance to keep this job?

- If yes, will you please describe to me what kind of assistance would be helpful?

10.) What skills have you gained while working at this enterprise? 
11.) Has this job connected you with housing, mental health services, benefits, or other resources?

- If so, will you please describe these connections to me?

12.) Have there been barriers to keeping this job?

- If yes, what are/were those barriers?

- How have you overcome them?

13.) Has this job prepared you for future jobs?

- If yes, how?

14.) Have you received support in your position from your employer? Examples of support include support in finding housing, developing job skills, emotional support or financial support.

- If so, please describe this support to me.

15.) Are there any additional forms of support that would help you to be successful in this position?

16.) What have been some of your successes while working here? Successes may include financial successes, personal successes, obtaining housing, acquiring new skills, etc.

- Have you obtained permanent housing while working at this job?

$\circ$ If so, how did you obtain housing?

- Have you had emotional successes, such as having feelings of self-fulfillment or accomplishment?

○ If yes, will you describe these feelings to me? If no, will you describe why you have not felt these feelings?

17.) Have you faced any struggles while working here financially, emotionally, with friends or family, with other commitments, or with mental health concerns?

- Have you been able to balance work with other commitments, such as family or friend obligations?

- If yes, will you please explain this balance to me? If no, will you please describe your struggles in balancing to me?

- Are you able to pay necessary bills each month with wages from this job?

$\circ$ If no, will you explain why? 


\section{Social Enterprise Characteristics}

18.) Please describe the culture of this enterprise. By culture, I mean the commonly understood beliefs, common rituals and ways of speaking, and ongoing ceremonies, meetings, or activities in an enterprise.

19.) As far as you are aware, does this enterprise partner with other businesses or agencies in the community?

20.) Please describe your professional relationship with your employer.

21.) Please describe your professional relationship with other employees.

- Are you friends with other employees?

- Do you feel supported by other employees?

○ If yes, will you explain the support? If no, will you explain the lack of support? 


\section{APPENDIX K. INTERVIEW QUESTIONS FOR MANAGERS/SUPERVIORS}

\section{Biography:}

1.) Please tell me a little bit about yourself and your role within this organization.

2.) What is your work and educational history?

- How long have you worked at this enterprise?

3.) Are you currently homeless? By homeless I mean lacking a place to sleep at night, including residing in an emergency shelter, on the streets, in a transitional housing unit, or a place not meant for human habitation.

- If so, for how long have you been homeless?

4.) Have you ever been homeless?

- If yes, when was your last period of homelessness?

- How long have you been homeless in total over your lifetime?

5.) Why do you work at this enterprise?

6.) How did you get your current position at this enterprise?

Experience Working at the Enterprise (This set of questions is asked only if the manager/supervisor is currently or formerly homeless)

7.) Do you need any workforce skills assistance and/or training to keep this job?

- If yes, will you please describe to me the workforce skills assistance and/or training that you need?

8.) Do you need support in terms of transportation, childcare, or housing assistance to keep this job?

- If yes, will you please describe to me what kind of assistance would be helpful?

9.) What skills have you gained while working at this enterprise?

10.) Has this job connected you with housing, mental health services, benefits, or other resources?

- If so, will you please describe these connections to me?

11.) Have there been barriers to keeping this job? 
- If yes, what are/were those barriers?

- How have you overcome them?

12.) Has this job prepared you for future jobs?

- If yes, how?

13.) Have you received support in your position from your employer? Examples of support include support in finding housing, developing job skills, emotional support or financial support.

- If so, please describe this support to me.

14.) Are there any additional forms of support that would help you to be successful in this position?

15.) What have been some of your successes while working here? Successes may include financial successes, personal successes, obtaining housing, acquiring new skills, etc.

- Have you obtained permanent housing while working at this job?

$\circ$ If so, how did you obtain housing?

- Have you had emotional successes, such as having feelings of self-fulfillment or accomplishment?

○ If yes, will you describe these feelings to me? If no, will you describe why you have not felt these feelings?

16.) Have you faced any struggles while working here financially, emotionally, with family and friends, with other commitments, or with mental health concerns?

- Have you been able to balance work with other commitments, such as family or friend obligations?

- If yes, will you please explain this balance to me? If no, will you please describe your struggles in balancing to me?

- Are you able to pay necessary bills each month with wages from this job?

If no, will you explain why?

Enterprise History (all participants):

17.) Please tell me a little bit about the mission and purpose of this organization.

18.) What would you say is the primary goal of this enterprise?

- What would you say are the economic goals of this enterprise (for example, making a profit)?

- What would you say are the social goals of your enterprise? (connecting the homeless with jobs or services) 
- Would you say that the primary goal of this enterprise is social (connecting the homeless with jobs or services), economic (making a profit), or a combination (such as selffulfillment)?

19.) How would you describe the culture of this enterprise? By culture, I mean the commonly understood beliefs, common rituals and ways of speaking, and ongoing ceremonies, meetings, or activities in an enterprise

Employees:

20.) How many employees do you supervise?

21.) Will you describe the employees in terms of gender, race/ethnicity and age?

22.) How many of the employees that you supervise are currently homeless? By homeless, I mean lacking a place to sleep at night, including residing in an emergency shelter, on the streets, in a transitional housing unit, or a place not meant for human habitation.

23.) How many of your employees are formerly homeless?

24.) On average at any given time, what percentage of your employees are homeless?

- What percentage are formerly homeless on average at any given time?

25.) What are your employees' estimated education levels (e.g., less than high school, high school graduate, vocational training, certifications, some college, college graduate, and some graduate school)?

26.) Do you offer job training opportunities for employees?

- If yes, what sorts of opportunities do you offer?

- How often do you offer these opportunities?

- Who coordinates job training opportunities?

- How many employees typically participate?

- Do you see a change in employee work performance after participating in job training opportunities?

- If yes, will you describe this change to me?

27.) Do you provide support for employees in finding housing or provide connections to other social services?

- If yes, what kinds of support do you offer?

- How often do you offer these supports?

- Who coordinates these supports? 
- How many employees utilize support opportunities?

- Do you see a change in work performance after an employee participates in these opportunities?

If yes, will you describe this change to me?

28.) On average, how long do non-managerial/non-supervisory employees usually stay at this enterprise?

- Where do they tend to go after leaving their job here?

29.) On average, how long do managerial/supervisory employees usually stay at this enterprise?

- Where do they tend to go after leaving their job here?

30.) Have you had successes at this enterprise in terms of your employees? If so, will you describe these successes?

- How many employees that are experiencing homelessness at the time of being first hired have you had since being a manager/supervisor at this enterprise?

- How many employees have gone on to find permanent housing who did not have housing prior to employment?

- Do you notice emotional changes in your employees, such as a sense of self-fulfillment, increased self-confidence, etc?

- How many employees have secured other jobs after working at this enterprise?

$\circ$ What kinds of jobs do employees tend to hold after working here?

31.) Have you had struggles at this enterprise in terms of employees? Examples of struggles may include hiring, retaining, training, or motivating employees. If yes, will you please explain these to me?

- What is your process for hiring employees?

○ Has this process changed over the years? If so, will you describe this change to me?

- How do you motivate employees?

o Have you had any difficulties motivating employees? If so, will you describe this difficulty?

32.) What barriers do you see to individuals experiencing homelessness gaining full-time employment in living wage jobs? By living wage I mean a wage that allows a person to afford housing, food, clothes, and sustain basic needs.

33.) What is your view regarding the labor market and what role employers can/should play in advancing or limiting job opportunities for homeless individuals? 
- Should employers offer job training for individuals experiencing homelessness?

○ Why or why not?

- Should employers provide transportation for employees experiencing homelessness to work?

○ Why or why not?

- Should employers offer childcare for homeless employees with children?

○ Why or why not?

- Should homeless employees hold managerial or supervisory positions at an enterprise?

$\circ$ Why or why not?

\section{Community}

34.) Do you partner with other businesses or agencies in the community?

- If yes, will you explain in what way(s) you collaborate?

35.) Is this business sustainable in the community? By that I mean, do you see your business remaining within the community for at least the next five years? Why or why not? 